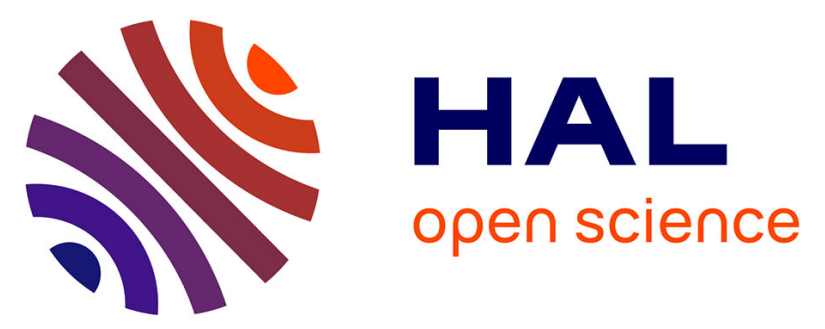

\title{
Conformational flexibility of coenzyme A and its impact on the post-translational modification of acyl carrier proteins by 4'-phosphopantetheinyl transferases
} Minh Chau Nguyen, Olivier Saurel, Coralie Carivenc, Sabine Gavalda, Stéphane Saitta, Mai Phuong Tran, Alain Milon, Christian Chalut, Christophe Guilhot, Lionel Mourey, et al.

\section{To cite this version:}

Minh Chau Nguyen, Olivier Saurel, Coralie Carivenc, Sabine Gavalda, Stéphane Saitta, et al.. Conformational flexibility of coenzyme A and its impact on the post-translational modification of acyl carrier proteins by 4'-phosphopantetheinyl transferases. FEBS Journal, 2020, 287, pp.4729 - 4746. 10.1111/febs.15273 . hal-02950584

\section{HAL Id: hal-02950584 https://hal.science/hal-02950584}

Submitted on 24 Nov 2020

HAL is a multi-disciplinary open access archive for the deposit and dissemination of scientific research documents, whether they are published or not. The documents may come from teaching and research institutions in France or abroad, or from public or private research centers.
L'archive ouverte pluridisciplinaire HAL, est destinée au dépôt et à la diffusion de documents scientifiques de niveau recherche, publiés ou non, émanant des établissements d'enseignement et de recherche français ou étrangers, des laboratoires publics ou privés. 


\section{Conformational flexibility of coenzyme $A$ and its impact on the post-translational modification of acyl carrier

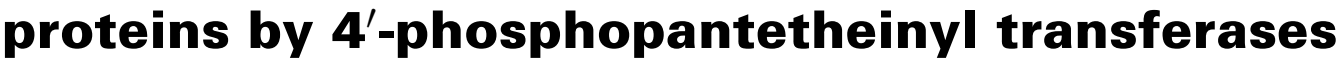

Minh Chau Nguyen, Olivier Saurel, Coralie Carivenc, Sabine Gavalda, Stéphane Saitta, Mai Phuong Tran, Alain Milon, Christian Chalut, Christophe Guilhot, Lionel Mourey and Jean-Denis Pedelacq

Institut de Pharmacologie et de Biologie Structurale (IPBS), Université de Toulouse, CNRS, UPS, Toulouse, France

\section{Keywords}

ACP; complex; modular PKS; PPTase;

protein dynamics

\section{Correspondence \\ J.-D. Pedelacq, Institut de Pharmacologie et de Biologie Structurale, IPBS, Université de Toulouse, CNRS, UPS, Toulouse, France Tel: +33561175496 \\ Email: jean-denis.pedelacq@ipbs.fr}

(Received 27 May 2019, revised 20 January 2020, accepted 29 February 2020)

doi:10.1111/febs.15273
One central question surrounding the biosynthesis of fatty acids and polyketide-derived natural products is how the 4'-phosphopantetheinyl transferase (PPTase) interrogates the essential acyl carrier protein (ACP) domain to fulfill the initial activation step. The triggering factor of this study was the lack of structural information on PPTases at physiological $\mathrm{pH}$, which could bias our comprehension of the mechanism of action of these important enzymes. Structural and functional studies on the family II PPTase PptAb of Mycobacterium abscessus show that $\mathrm{pH}$ has a profound effect on the coordination of metal ions and on the conformation of endogenously bound coenzyme A ( $\mathrm{CoA})$. The observed conformational flexibility of $\mathrm{CoA}$ at physiological $\mathrm{pH}$ is accompanied by a disordered $4^{\prime}$ phosphopantetheine (Ppant) moiety. Finally, structural and dynamical information on an isolated mycobacterial ACP domain, in its apo form and in complex with the activator PptAb, suggests an alternate mechanism for the post-translational modification of modular megasynthases.

\section{Introduction}

Metabolites synthesized by fatty acid synthases (FASs), polyketide synthases (PKSs), and non-ribosomal peptide synthetases (NRPSs) include a broad range of complex organic compounds with biological activities that have been widely exploited in the discovery of new therapeutic agents [1]. Members of the Mycobacterium genus are unique among prokaryotes as they have both type I and type II FAS systems that they use in combination with type I PKS to produce essential cell envelope components and lipid virulence factors [2]. Mycobacteria belong to either the Mycobacterium tuberculosis complex (MTBC) or the nontuberculous mycobacteria (NTM). MTBC contains the etiologic agents of the tuberculosis disease including M. tuberculosis, whereas NTM such as Mycobacterium abscessus can cause lung infection, especially in patients with pulmonary diseases such as cystic fibrosis or bronchiectasis $[3,4]$.

The central player throughout the synthesis of primary and secondary metabolites in living cells across all three domains of life is the carrier protein $(\mathrm{CP})$ domain, a small ( $\sim 80$ residues), noncatalytic, and post-translationally modified domain. The post-translational modification is catalyzed by a $4^{\prime}$-phosphopantetheinyl transferase (PPTase), which transfers the 4'phosphopantetheine (Ppant) moiety from a coenzyme

\footnotetext{
Abbreviations

3',5'-ADP, adenosine 3',5'-diphosphate; AASDHPPT, Homo sapiens PPTase; ACP, acyl carrier protein; CoA, coenzyme A; DSF, differential scanning fluorimetry; MTBC, Mycobacterium tuberculosis complex; MuPPT, Mycobacterium ulcerans PPTase; NMR, nuclear magnetic resonance; NTM, nontuberculous mycobacteria; PKS, polyketide synthase; Ppant, 4'-phosphopantetheine; PptAb, Mycobacterium abscessus PPTase; PPTase, 4'-phosphopantetheinyl transferase; PptT, Mycobacterium tuberculosis PPTase; Sfp, Bacillus subtilis surfactin phosphopantetheinyl transferase; urea/PAGE, urea/polyacrylamide gel electrophoresis.
} 
A (CoA) molecule onto a strictly conserved serine residue, in the presence of metal ions $\mathrm{Mg}^{2+}$ or $\mathrm{Mn}^{2+}[5,6]$. The thiol at the extremity of the Ppant prosthetic group ( $\sim 20 \AA$ long) then serves as an anchor for the proper elongation and modification of intermediate products via interactions with their cognate enzymes.

The PPTase superfamily can be divided into three families based on their target synthases, phylogenic distributions and sequence alignments, and three-dimensional structures [7]. Family I PPTases are the modifying enzymes for acyl carrier protein (ACP) involved in prokaryotic fatty acid biosynthesis. They are relatively short in size, between 120 and 140 amino acid residues, and form obligatory trimers with three active sites. An archetypal member of this group is AcpS of Bacillus subtilis [5]. Family II PPTases activate secondary metabolite biosynthetic pathways. They exist as pseudo-homodimers of 220-240 amino acid residues, resembling two AcpS monomers with one active site at the pseudo-dimer interface. The first representative of this group is the surfactin phosphopantetheinyl transferase (Sfp) from B. subtilis, the reference enzyme when it comes to performing in vitro activity assays for holo-CP synthesis. Family III PPTases are mainly found in fungi, where they form distinct catalytic domains within the FAS complex [8]. Investigations of the excised PPT domain of FAS from yeast showed that it forms catalytic trimers analogous to family I PPTases. It was proposed that trimerization occurs during the assembly of the active FAS enzyme complex [9].

Mycobacterium tuberculosis contains two PPTases with nonredundant functions: AcpS, which activates type I and type II FAS enzymes, and PptT, in charge of the activation of all type I PKSs and NRPSs $[10,11]$. More recently, it has been shown that PptT could also activate the meromycolate extension ACP (AcpM) of type II FAS system in vitro [12]. M. abscessus also produces two PPTases [13], PptAb (UniProt entry B1MD73) and AcpS (UniProt entry B1MMN7), which share $67 \%$ and $73 \%$ sequence identity with PptT and AcpS of M. tuberculosis, respectively. Given the conservation of genes and biosynthetic pathways involved in the synthesis of lipids in mycobacteria, it is likely that PptAb also mediates biosynthesis of structurally and functionally important lipids in this microorganism and that it is essential for the survival of the bacteria in various environments. Furthermore, $\mathrm{PptAb}$ is probably required for the activation of diverse PKSs and NRPSs involved in the production of compounds such as glycopeptidolipids and siderophores that contribute to the virulence of $M$. abscessus $[14,15]$.
The triggering factor of this study was the acidic nature of known crystallization conditions of family II PPTases, which could bias our understanding of the mechanism of action of these important enzymes [1618]. Here, we present an in-depth description of the effect of $\mathrm{pH}$ on the binding of $\mathrm{CoA}$ and metal ions in PptAb. The most significant results include (a) an increased stability of PptAb in the presence of $\mathrm{Mn}^{2+}$ rather than $\mathrm{Mg}^{2+}$ ions at acidic and neutral $\mathrm{pH}$, (b) a change in the conformation of the Ppant moiety of $\mathrm{CoA}$ from a well-ordered state at acidic $\mathrm{pH}$ to a disordered state at physiological $\mathrm{pH}$, (c) a trapped $\mathrm{CoA}$ with a new conformation in the X-ray structure of $\mathrm{PptAb}$ in complex with a cognate ACP domain at physiological $\mathrm{pH}$, and (d) free-standing ACP internal motions localized in the region in contact with PptAb, as revealed by NMR relaxation experiments. Altogether, these results contribute to a better understanding of the activation of ACP domains by mycobacterial PPTases.

\section{Results}

\section{Bound cofactors in family II PPTases at acidic pH}

PptAb of M. abscessus adopts the typical pseudodimeric structure of family II PPTases consisting of two $\alpha / \beta$ domains related by a pseudo-twofold symmetry with CoA spanning across the cavity (Fig. 1A). Best structural homologues from mycobacterial species superimpose closely with $\mathrm{C} \alpha$ rmsd values of $\sim 1 \AA$ for $\sim 220$ aligned residues. At acidic pH, CoA in PptAb adopts a conformation similar to the one observed in the X-ray structures of PptT from M. tuberculosis and MuPPT from Mycobacterium ulcerans [16]. The aminothiol group of CoA is buried inside a deep pocket mostly dominated by hydrophobic contacts. There is one polar interaction between the main-chain carbonyl of Leu167 and the aminothiol group of CoA that is also conserved in the structures of PptT and MuPPT (Fig. 1A, close-up view). The pocket entrance is delineated by the side chains of residues Glu153, Tyr156, Trp166, and Phe169 (Fig. 1A, close-up view). A multiple sequence alignment including over one hundred and thirty rapidly and slowly growing Mycobacterium species [19] revealed that all four residues are strictly conserved. With the exception of the catalytic Glu153, none of these residues is conserved in the Sfp [17] and human PPTase [18] enzymes where the Ppant adopts a conformation different from that of mycobacterial PPTases (Fig. 2). The position of the $3^{\prime}, 5^{\prime}$-ADP moiety of CoA in PptAb is also similar to that of PptT and MuPPT. Stabilization occurs through 

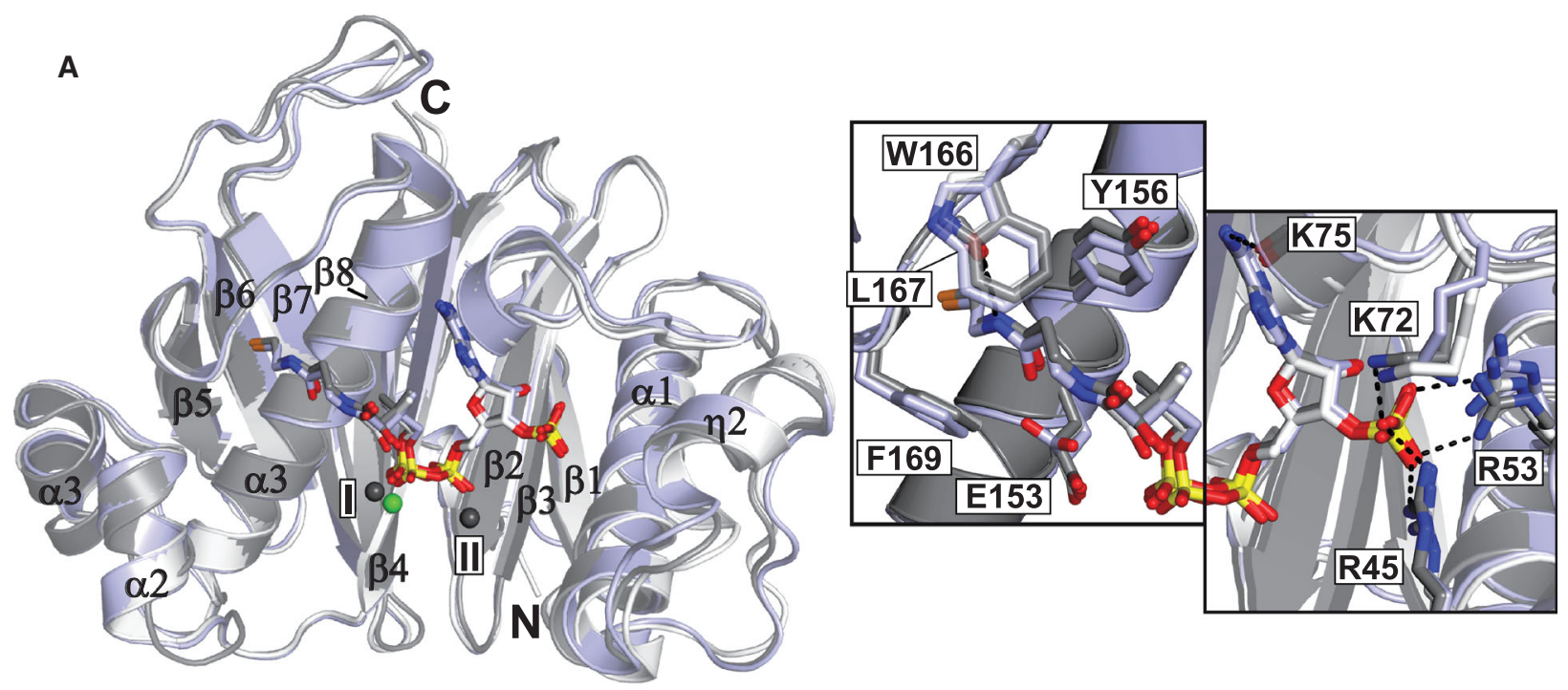

B

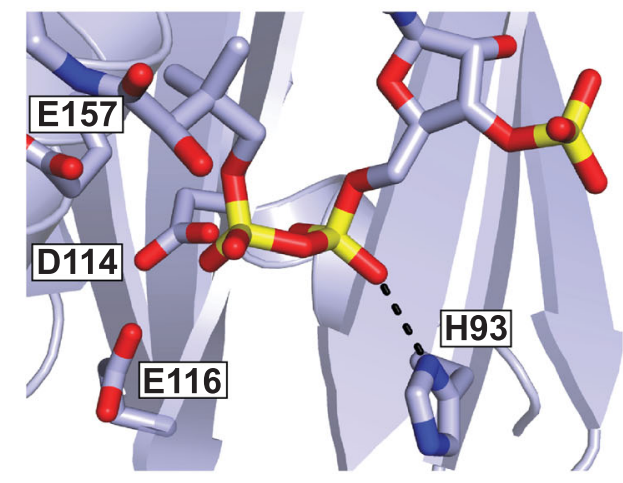

D

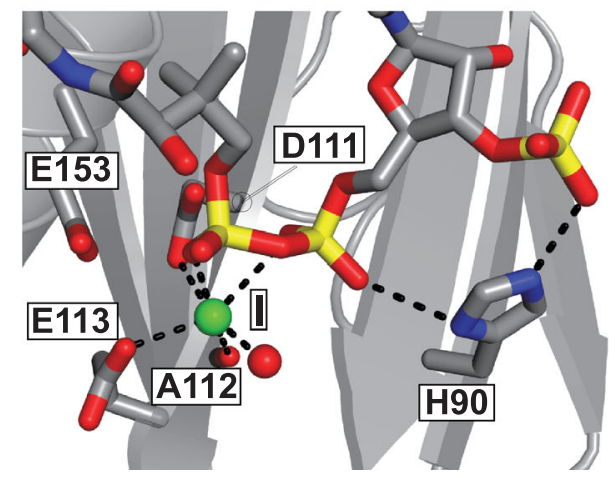

C

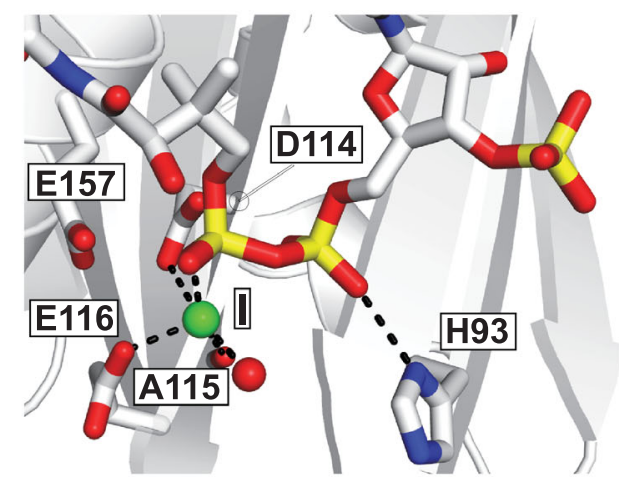

E

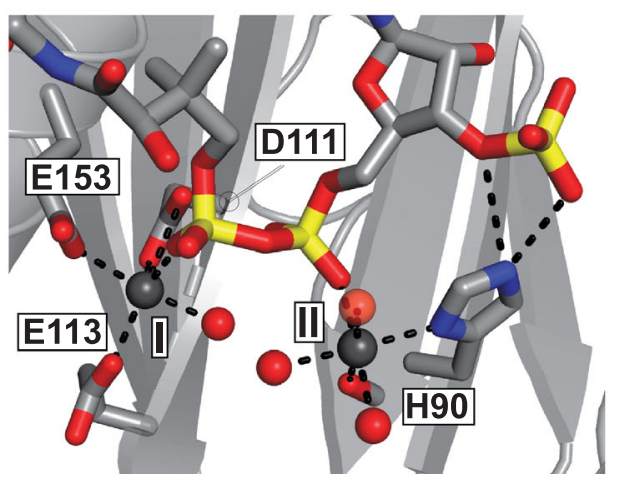

Fig. 1. X-ray structures of mycobacterial PPTases at acidic $\mathrm{pH}$. (A) Structural superimposition of PptAb from Mycobacterium abscessus (PDB code 6QWU, in gray) onto its homologues from Mycobacterium tuberculosis (PptT, PDB code 4U89 in blue) and M. ulcerans (MuPPT, PDB code 4QJL in white). Right, side chains of conserved residues interacting with the $3^{\prime}, 5^{\prime}$-ADP and Ppant moieties are represented using the same color code. $\mathrm{Mg}^{2+}$ and $\mathrm{Mn}^{2+}$ ions at binding sites I and II are represented as green and gray spheres, respectively. The polar interaction between the main-chain carbonyl of Leu167 and the aminothiol group of CoA is shown. Close-up view of the cofactor binding site in (B) PptT (PDB code 4U89) and (C) MuPPT (PDB code 4QJL) crystallized at pH 4.5 and 5.5, respectively. Close-up view of the CoA binding site in PptAb at acidic pH with (D) one $\mathrm{Mg}^{2+}$ (PDB code 6OYF) and (E) two $\mathrm{Mn}^{2+}$ (PDB code 6QWU). $\mathrm{Mn}^{2+}$ at site I is shifted by $\sim 1.7 \AA$ with coordination to the active site residue Glu153. CoA and residues are shown as sticks (nitrogen, blue; oxygen, red; phosphate, yellow; and sulfur, orange). Water molecules are represented as red balls. Figures were generated using PYMOL (The PyMOL Molecular Graphics System, version 2.0; Schrödinger, LLC). 

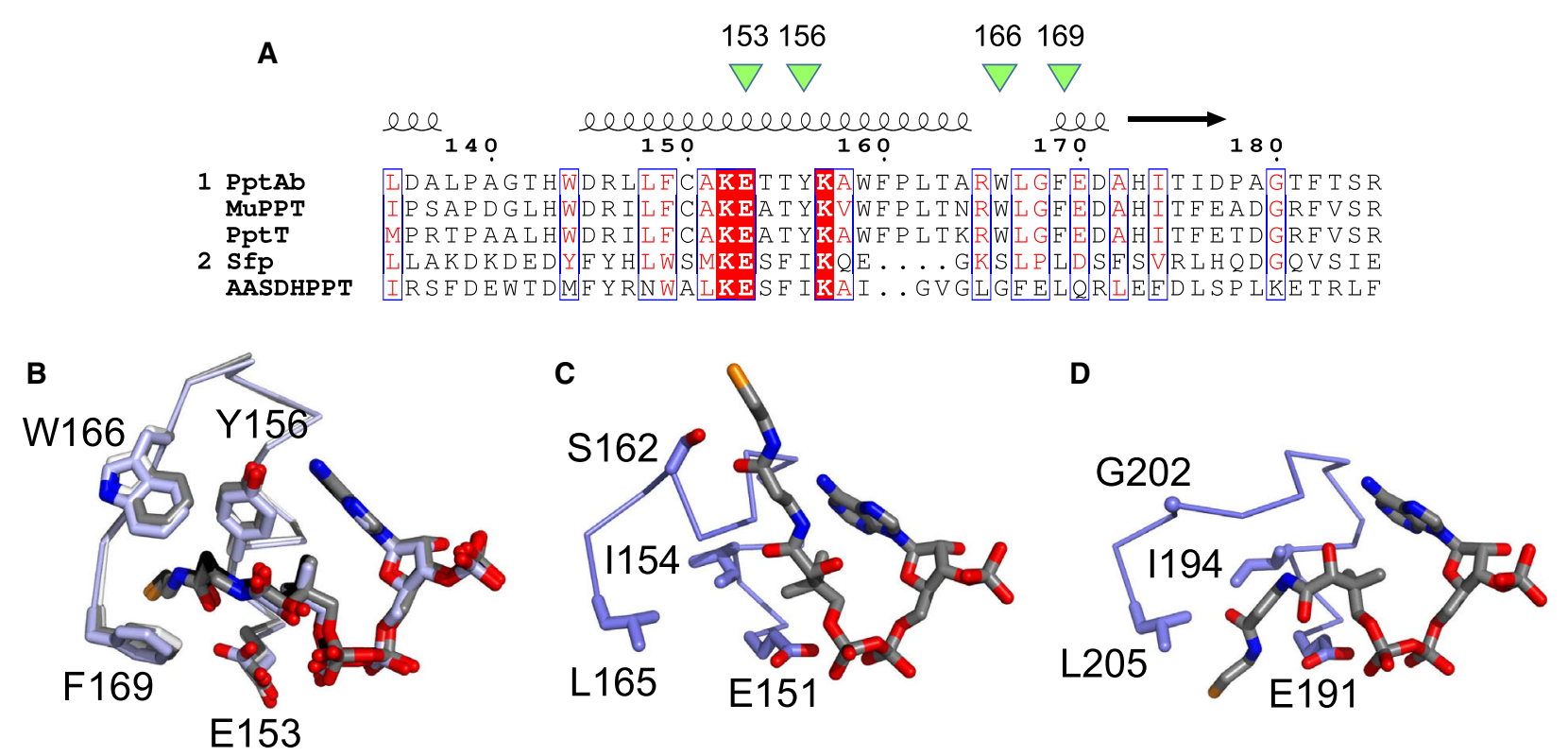

Fig. 2. The Ppant tunnel entrance. Related to Fig. 1. (A) Structure-based sequence alignment of the PPTase from Mycobacterium abscessus (PptAb, UniProt entry B1MD73) with homologues from M. ulcerans (MuPPT, UniProt entry A0PQD8) and Mycobacterium tuberculosis (PptT, UniProt entry O33336), extended to Sfp from Bacillus subtilis (UniProt entry P39135) and the human AASDHPPT (UniProt entry Q9NRN7). Residues delineating the Ppant entrance in the mycobacterial PPTases are indicated. (B) Close-up view of the Ppant entrance in the X-ray structures of PptAb (gray), MuPPT (PDB code 4QJL, white), and PptT (PDB code 4U89, blue). The side chains of conserved residues and coenzyme $A$ are shown as sticks (nitrogen, blue; oxygen, red; and sulfur, orange). The Ppant moiety of (C) Sfp (PDB code 4MRT) and (D) AASDHPPT (PDB code 2C43) points outside the cavity. The structure-based alignments were displayed using ESPRIPT [49]. Structure figures were generated using PYMOL (The PYMOL Molecular Graphics System, version 2.0; Schrödinger, LLC).

numerous polar interactions between the protein and the $3^{\prime}$-phosphate group, the adenine ring, and the $\alpha$ phosphate. Interactions involving the ribose phosphate are quite remarkable as the side-chain amides of Arg45, Arg53, and Lys72 form the apex of a triangle with the phosphate at the center (Fig. 1A, close-up view). Despite the fact that all three residues are strictly conserved among characterized Mycobacterium species, networks of interactions slightly differ in the three mycobacterial PPTase structures (Fig. S1).

All known family II PPTase structures have a single cation binding site occupied by $\mathrm{Mg}^{2+}$, designated as site I, that interacts directly with the $\beta$-phosphate of $\mathrm{CoA}$ and is required for activity [7]. The acidic nature of the crystallization conditions may be responsible for the absence of $\mathrm{Mg}^{2+}$ in the high-resolution structures of PptT determined by us (PDB code 4U89) and others [16] (Fig. 1B). The hypothesis that side chains of negatively charged residues in PptT become protonated, thereby reducing their ability to effectively coordinate $\mathrm{Mg}^{2+}$, was later supported by the presence of this metal ion in the MBP-PptT structure [20]. The coordination spheres identified in the structures of MuPPT (Fig. 1C) and PptAb (Fig. 1D) involve the $\beta$ phosphate of CoA, the side chains of two acidic residues, Asp111 and Glu113 (PptAb numbering), and the main-chain carbonyl group of Ala112, in addition to one ordered water molecule. At acidic $\mathrm{pH}$, an unexpected consequence of replacing $\mathrm{Mg}^{2+}$ with $\mathrm{Mn}^{2+}$ is that site I has shifted $1.7 \AA$ toward residue Glu153 (Fig. 1E). This conserved Glu153 is the catalytic base in charge of deprotonating the serine residue of the ACP acceptor domain, prior to transfer of the Ppant arm $[6,18]$.

The X-ray structure of PptAb also revealed the presence of a second metal binding site, designated site II, with a stronger preference for $\mathrm{Mn}^{2+}$ over $\mathrm{Mg}^{2+}$ ions (Fig. 1E). The imidazole group of His90, which is rotated away by $\sim 50^{\circ}$ from the position it occupies in the structures of PptT (Fig. 1B) and MuPPT (Fig. 1C), interacts with $\mathrm{Mn}^{2+}$ and the $3^{\prime}$-phosphate of CoA via the $\delta$ - and $\varepsilon$-nitrogens, respectively. Up to three water molecules complete the coordination sphere. PptAb crystallized in the presence of $\mathrm{Mg}^{2+}$ often exhibits residual density at site II that could not be assigned to a metal ion. However, the imidazole group of His 90 adopts the same conformation as in the structure with bound $\mathrm{Mn}^{2+}$ (Fig. 1D). This mere pivoting movement, also present in the structures of Sfp [17] and human AASDHPPT [18], may coincide 
with the presence of a divalent ion with low occupancy.

\section{The X-ray structure of PptAb at physiological pH reveals a disordered Ppant moiety}

As mentioned above, only limited structural information on family II PPTases at neutral $\mathrm{pH}$ is available. We were then eager to see how a physiologically relevant $\mathrm{pH}$ could influence the binding of $\mathrm{CoA}$ and divalent ions. We crystallized $\mathrm{PptAb}$ at $\mathrm{pH}$ values ranging from 6.5 to 8.5 in the presence of either $\mathrm{Mn}^{2+}$ or $\mathrm{Mg}^{2+}$, and accumulated several high-resolution structures (Tables 1 and 2). Contrary to PptAb at acidic $\mathrm{pH}$ where the CoA is easily identifiable in a simulatedannealing (SA) omit map contoured at $1 \sigma$ (Fig. 3A, top left), we noticed that, at $\mathrm{pH} 7$ or higher, the Ppant moiety could not be modeled due to poor electron density from a refined $2 \mathrm{Fo}-\mathrm{Fc}$ map contoured at $1 \sigma$ (Fig. 3B, top left and Fig. S2). A careful examination of the active site cavity revealed that the orientation of the side chains and their interactions with $\mathrm{CoA}$ and divalent cations are mostly identical (Fig. 3A,B, right). A plausible explanation for the conformational mobility of Ppant may come from a subtle change in the distribution of charges at the surface of the protein, slightly positive at $\mathrm{pH} 5.6$ (Fig. 3A, bottom left) and negative at physiological $\mathrm{pH}$ (Fig. 3B, bottom left). The recently described crystal structure of $\mathrm{PptT}$ at $\mathrm{pH}$ 6.7 also confirms the absence of the Ppant arm in the pocket [21]. Nevertheless, the proposed role of the bound amidino-urea compound called '8918', which would be responsible for the Ppant displacement outside the tunnel, is perhaps overstated.

\section{Stability and activity of PptAb}

Using freshly prepared PptAb purified in Tris buffer at pH 7.0 supplemented with an excess of $\mathrm{MgCl}_{2}$ (see Materials and methods), we could measure a melting temperature $\left(T_{\mathrm{m}}\right)$ value of $37.5 \pm 0.2{ }^{\circ} \mathrm{C}$ (Fig. 4A). We then tested the influence of $\mathrm{Mn}^{2+}$ on the stability of PptAb, a divalent ion also known to catalyze the Ppant transfer reaction [5,6]. By simply replacing $\mathrm{MgCl}_{2}$ with $\mathrm{MnCl}_{2}$ in the purification protocol, the measured $T_{\mathrm{m}}$ value increased by $\sim 16{ }^{\circ} \mathrm{C}$ at $53.4 \pm 0.2{ }^{\circ} \mathrm{C}$. Similar effect was observed by adding $\mathrm{MnCl}_{2}$ to the PptAb/ $\mathrm{MgCl}_{2}$ mixture, with a $T_{\mathrm{m}}$ value at $47.4 \pm 0.2{ }^{\circ} \mathrm{C}$. Higher $T_{\mathrm{m}}$ values above $60{ }^{\circ} \mathrm{C}$ could be measured by adding an excess of $\mathrm{CoA}$ to PptAb purified in the presence of either $\mathrm{Mg}^{2+}$ or $\mathrm{Mn}^{2+}$.

The enzymatic activity of PptAb was analyzed in vitro in the presence of a fragment encompassing the ACP domain of the type I polyketide synthase PpsC of M. tuberculosis (UniProt entry P96202). This well-expressed and soluble fragment, which incorporates the predicted ACP domain (from residue 2057 to 2145 ) in addition to the C-terminal linker (from residue 2146 to 2188) of $\mathrm{PpsC}$, was identified using the domain trapping method [22]. It was produced in Escherichia coli BL21(DE3) cells missing the endogenous PPTase EntD [11] and purified using a one-step protocol (see Materials and methods). We evaluated the effect of $\mathrm{pH}$ on the transfer of the Ppant moiety of $\mathrm{CoA}$ on the ACP fragment in the presence of either $\mathrm{Mg}^{2+}$ or $\mathrm{Mn}^{2+}$, as previously described [23]. At $\mathrm{pH} 7$, a transfer of the Ppant moiety is detected on a $10 \%$ urea/PAGE in the presence of either cation. On the other hand, only $\mathrm{Mn}^{2+}$ can permit the transfer reaction at acidic $\mathrm{pH}$, in good agreement with the increased stability of PptAb in the presence of this metal ion (Fig. 4B).

\section{Snapshot of a Ppant transfer intermediate trapped into the X-ray structure of the PptAb/ ACP complex at physiological $\mathrm{pH}$}

A question raised by the structural analysis of PptAb at physiological $\mathrm{pH}$ concerns the spatial organization of the Ppant of CoA prior to its transfer on the conserved serine residue of an ACP partner. The phosphopantetheinylated Ser2105 of the ACP domain of PpsC was mutated to an alanine to favor the formation of a stable ternary complex, as described for the X-ray structures of Sfp in complex with a peptidyl carrier protein (PCP) domain [24] and AASDHPPT in complex with an ACP domain from FAS [18]. The ACP fragment was mixed in a $1: 1$ molar ratio with PptAb purified in the presence of $\mathrm{MnCl}_{2}$, prior to crystallization trials (see Materials and methods). The X-ray structure of the PptAb-ACP complex was determined to a resolution of $2.0 \AA$ (Table 2). Fifty-three residues located either at the $\mathrm{N}$ - or at the C-terminal end of the selected ACP fragment (positions 2057-2069 and 2145-2188) show poorly defined electron density and hence have not been modeled in the complex structure.

The ACP domain of PpsC consists of four $\alpha$-helices $(\alpha 1$ to $\alpha 4)$ and one short $3_{10}$ helix $\eta 1$, with the modified serine residue (S2105A) located at the $\mathrm{N}$-terminal extremity of helix $\alpha 2$ (Fig. 5A). The ACP domain is structurally closer to its homologue in the bacterial Sfp-PCP complex [24] with a rmsd of $1.2 \AA$ over 72 out of $76 \mathrm{C} \alpha$ atoms, compared with a rmsd of $2.7 \AA$ over 65 out of $71 \mathrm{C} \alpha$ atoms for the human ACP in complex with AASDHPPT [18]. The buried solvent-accessible surface area in the PptAb-ACP interface of 


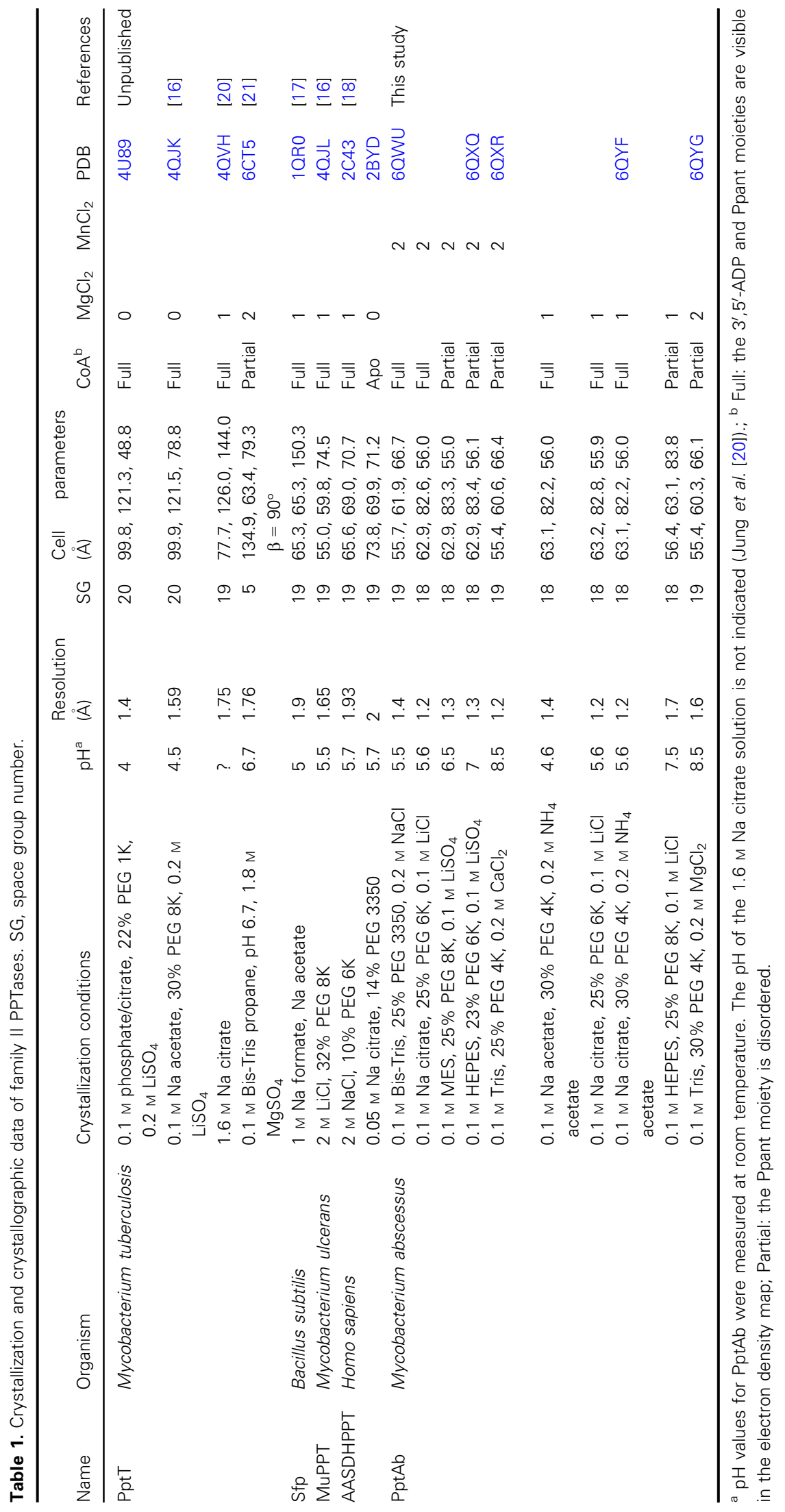


Table 2. Data collection and refinement statistics. Statistics for the highest-resolution shell are shown in parentheses.

\begin{tabular}{|c|c|c|c|c|c|c|}
\hline Name & PptAb & & & & & PptAb-ACP \\
\hline PDB code & $60 W U$ & $60 \times 0$ & $60 \times R$ & 6QYF & $6 Q Y G$ & $6 \mathrm{RCX}$ \\
\hline Wavelength & 0.967700 & 0.972422 & 1.072270 & 0.967700 & 0.972422 & 0.976247 \\
\hline $\mathrm{pH}$ & 5.5 & 7 & 8.5 & 5.6 & 8.5 & 6.5 \\
\hline Metal ion & $\mathrm{Mn}^{2+}$ & $\mathrm{Mn}^{2+}$ & $\mathrm{Mn}^{2+}$ & $\mathrm{Mg}^{2+}$ & $\mathrm{Mg}^{2+}$ & $\mathrm{Mn}^{2+}$ \\
\hline Resolution range & $\begin{array}{l}45.38-1.40(1.45 \\
-1.40)\end{array}$ & $\begin{array}{l}41.71-1.45(1.50 \\
-1.45)\end{array}$ & $\begin{array}{l}44.75-1.20(1.24 \\
-1.20)\end{array}$ & $\begin{array}{l}28.00-1.40(1.45 \\
-1.40)\end{array}$ & $\begin{array}{l}42.46-1.60(1.66 \\
-1.60)\end{array}$ & $\begin{array}{l}41.15-2.00(2.07 \\
-2.00)\end{array}$ \\
\hline Space group & P 212121 & P 21212 & P 212121 & P 21212 & P 212121 & P 212121 \\
\hline Unit cell $(\AA)$ & 55.761 .966 .7 & 62.983 .456 .1 & 55.460 .666 .4 & 63.182 .256 .0 & 55.460 .366 .1 & 50.163 .2108 .5 \\
\hline Total reflections & 302522 (21 374) & $277588(25754)$ & $219244(20146)$ & 375120 (26 989) & 161206 (16 095) & 127928 (12 069) \\
\hline Unique reflections & 45439 (4151) & $52990(5216)$ & 68697 (6756) & 56325 (4954) & 29270 (2855) & 23870 (2318) \\
\hline Multiplicity & $6.7(5.1)$ & $5.2(4.9)$ & $3.2(3.0)$ & $6.7(5.4)$ & $5.5(5.6)$ & $5.4(5.2)$ \\
\hline Completeness (\%) & $98.6(91.5)$ & 99.7 (99.5) & $97.6(97.4)$ & $97.0(87.1)$ & $98.0(97.3)$ & $99.6(99.2)$ \\
\hline Mean //sigma (/) & $13.5(1.7)$ & $13.5(1.7)$ & $13.1(2.1)$ & $22.2(4.3)$ & $13.5(2.2)$ & $14.2(2.5)$ \\
\hline Wilson B-factor & 14.9 & 21.0 & 12.5 & 13.0 & 18.9 & 35.1 \\
\hline R-merge & $0.075(0.841)$ & $0.062(0.831)$ & $0.041(0.511)$ & $0.050(0.375)$ & $0.072(0.710)$ & $0.072(0.531)$ \\
\hline R-meas & $0.082(0.938)$ & $0.069(0.931)$ & $0.049(0.621)$ & $0.055(0.415)$ & $0.080(0.782)$ & $0.080(0.591)$ \\
\hline $\mathrm{CC} 1 / 2$ & $0.998(0.648)$ & $0.998(0.736)$ & $0.999(0.724)$ & $0.999(0.956)$ & $0.998(0.797)$ & 0.998 (0.929) \\
\hline \multicolumn{7}{|l|}{ Reflections used in } \\
\hline Refinement & 45429 (4150) & 52955 (5211) & 68695 (6756) & 56311 (4954) & 29268 (2856) & 23853 (2318) \\
\hline R-free & 1939 (177) & $775(75)$ & $1629(161)$ & $1589(140)$ & $1321(126)$ & $1712(166)$ \\
\hline R-work & $0.164(0.340)$ & $0.167(0.299)$ & $0.160(0.283)$ & $0.149(0.266)$ & $0.181(0.281)$ & $0.206(0.309)$ \\
\hline R-free & $0.181(0.345)$ & $0.195(0.327)$ & $0.178(0.304)$ & $0.164(0.311)$ & $0.195(0.280)$ & $0.243(0.324)$ \\
\hline $\mathrm{Nb}$ of non-H atoms & 2104 & 2140 & 2142 & 2251 & 2071 & 2439 \\
\hline Macromolecules & 1716 & 1701 & 1701 & 1706 & 1724 & 2239 \\
\hline Ligands & 58 & 29 & 30 & 49 & 33 & 56 \\
\hline Solvent & 330 & 410 & 411 & 496 & 314 & 144 \\
\hline Protein residues & 219 & 218 & 220 & 218 & 219 & 292 \\
\hline RMS(bonds) & 0.016 & 0.010 & 0.006 & 0.009 & 0.010 & 0.007 \\
\hline RMS(angles) & 1.35 & 1.12 & 0.96 & 1.05 & 0.87 & 0.71 \\
\hline \multicolumn{7}{|l|}{ Ramachandran } \\
\hline Favored (\%) & 99.5 & 100.0 & 99.5 & 98.6 & 99.5 & 97.9 \\
\hline Allowed (\%) & 0.5 & 0.0 & 0.5 & 1.4 & 0.5 & 2.1 \\
\hline Outliers (\%) & 0.0 & 0.0 & 0.0 & 0.0 & 0.0 & 0.0 \\
\hline $\begin{array}{l}\text { Rotamer outliers } \\
(\%)\end{array}$ & 0.5 & 1.1 & 2.2 & 1.6 & 1.1 & 1.3 \\
\hline $\begin{array}{l}\text { Average B-factor } \\
\left(\AA^{2}\right)\end{array}$ & 22.5 & 30.2 & 19.8 & 21.6 & 24.1 & 50.4 \\
\hline Macromolecules & 20.7 & 27.3 & 17.3 & 17.4 & 22.4 & 50.5 \\
\hline Ligands & 17.4 & 20.7 & 11.8 & 12.0 & 21.4 & 51.4 \\
\hline Solvent & 32.4 & 42.8 & 31.0 & 36.7 & 33.2 & 47.6 \\
\hline
\end{tabular}

$\sim 660 \AA^{2}$ per subunit is mostly driven by van der Waals contacts and water-mediated polar contacts with a remarkable shape complementarity compared with Sfp-PCP (Fig. 5B) and AASDHPPT-ACP (Fig. 5C). The buried surface is slightly smaller than the one observed for the Sfp-PCP and AASDHPPTACP complexes, with respective values of 720 and $850 \AA^{2}$. In addition, networks of polar interactions at the interface differ significantly in the three complexes.

A detailed examination of the PptAb-ACP interface shows that the ACP domain is anchored to two short protein segments of PptAb, named S1 (positions 40-
45) and S2 (positions 118-126), responsible for the majority of polar and hydrophobic interactions with the ACP substrate (Fig. 5A, left). The unique polar interaction between $\mathrm{CoA}$ and the ACP domain involves an oxygen of the $\beta$-phosphate and the mainchain nitrogen of the mutated Ser-to-Ala amino acid at position 2105. One of the most intriguing results concerns the Ppant transition from a disordered state in the structure of PptAb to an ordered state in the PptAb-ACP complex at physiological pH. One nonpolar interaction holds our attention as the indole ring of Trp2129 (helix $\alpha 3$ ) stacks onto the segment $\mathrm{CH}(\mathrm{OH})$ - 
A
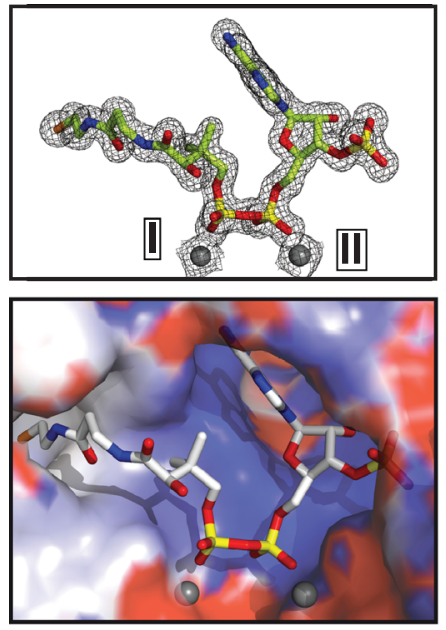

B
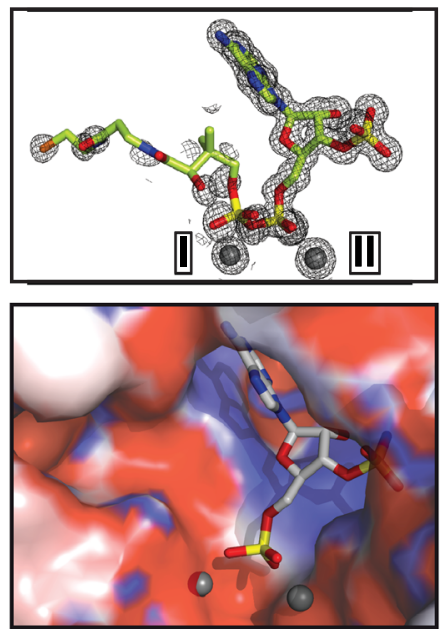
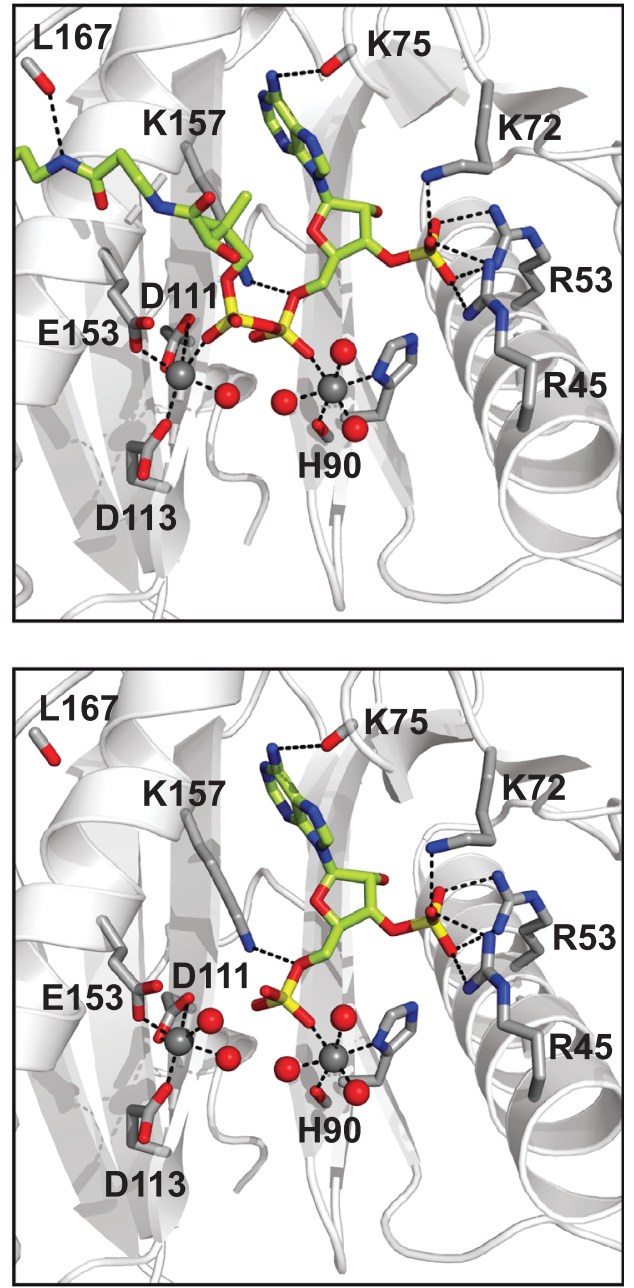

Fig. 3. Effect of $\mathrm{pH}$ on $\mathrm{CoA}$ binding in PptAb. Structural analysis of PptAb from Mycobacterium abscessus crystallized at $\mathrm{pH}$ (A) 5.5 (PDB code 60WU) and (B) $\mathrm{pH} 7$ (PDB code 6QXQ) in the presence of $\mathrm{Mn}^{2+}$. Clockwise, electron density 2Fo-Fc SA omit maps contoured at $1 \sigma$, interaction between cofactors and residues of PptAb, and electrostatic surface potential of PptAb. Blue shading $\left(+5 k_{\mathrm{B}} T / e\right)$ and red shading $\left(-5 k_{\mathrm{B}} T / e\right)$ indicate electropositive and electronegative protein surfaces, respectively. The Ppant moiety shows poorly defined electron density at physiological $\mathrm{pH}$. CoA and residues are shown as sticks (nitrogen, blue; oxygen, red; phosphate, yellow; and sulfur, orange). Water molecules and $\mathrm{Mn}^{2+}$ ions are displayed as red and gray spheres, respectively. Figures were generated using PYMOL (The PyMOL Molecular Graphics System, version 2.0; Schrödinger, LLC).
$\mathrm{CO}-\mathrm{NH}-\mathrm{CH} 2-\mathrm{CH} 2$ of the pantothenic portion of $\mathrm{CoA}$ (Fig. 5A, right), normally disordered in the structure of PptAb at physiological $\mathrm{pH}$. In the Sfp-PCP complex, the same type of interactions is accomplished by a Phe at position 69 with its phenyl group against the pantothenic group of $\mathrm{CoA}$ (Fig. 5B, right). On the other hand, replacement of the aromatic amino acid with an Arg (Arg2163) in the human AASDHPPTACP complex may be responsible for the disordered Ppant moiety (Fig. 5C, right).

Unexpectedly, the $\mathrm{P}_{\alpha}-\mathrm{O}-\mathrm{P}_{\beta}$ angle of the pyrophosphate group is flipped by $\sim 180^{\circ}$ from the position it occupies in previously described family II PPTase structures, including PptAb at acidic pH (Fig. 6A). Structural changes propagate as far as $\sim 10 \AA$ along the pantothenic acid group, whereas the $\beta$-mercaptoethylamine extremity remains spatially constricted inside the hydrophobic pocket. To the exception of a water molecule that replaces the oxygen atom of the $\beta$-phosphate group of CoA, positions of the two $\mathrm{Mn}^{2+}$ ions and residues within the active site cavity of PptAb are unaffected by interactions with the ACP substrate (Fig. 6A,B).

Structural and mutational studies on family II PPTases Sfp [17], AASDHPPT [18], and PptT [16] have suggested a reaction mechanism starting with the deprotonation of the hydroxyl group of the serine acceptor by a conserved glutamate side chain (Glu153 in PptAb) followed by the nucleophilic attack on the pyrophosphate group (Fig. 6C). Although such a mechanism can be transposed to the PptAb-ACP complex, the fact remains that the metal-bound water molecule could serve as an intermediate to abstract a proton from Ser2105. Indeed, a rotation of the $\mathrm{C} \alpha-\mathrm{C} \beta$ bond of Ser2105 could place the hydroxyl hydrogen adjacent to the water molecule. This alternate mechanism implies the activation of the ordered water molecule by the nearby Glu153, which then deprotonates 
Fig. 4. Biophysical and biochemical characterization of PptAb. (A) Thermal stability of PptAb produced and purified in the presence of $\mathrm{Mg}^{2+}$ (light blue) or $\mathrm{Mn}^{2+}$ (light orange). Error bars are defined as mean $\pm \mathrm{SD}, n=3$. Subsequent addition of $\mathrm{Mn}^{2+}$ or $\mathrm{CoA}$ to PptAb/Mg ${ }^{2+}$ and CoA to $\mathrm{PptAb} / \mathrm{Mn}^{2+}$ greatly increases the stability of the enzyme. Fluorescence emission measurements were monitored at $610 \mathrm{~nm}$ from $18{ }^{\circ} \mathrm{C}$ to $80^{\circ} \mathrm{C}$. (B) Activation time course of the ACP domain by the PPTases Sfp and PptAb. The transfer of the Ppant group from CoA to the ACP domain of PpsC is visualized on a $10 \%$ native polyacrylamide gel supplemented with $2.5 \mathrm{M}$ urea in the presence of $\mathrm{MgCl}_{2}$ or $\mathrm{MnCl}_{2}$ at different time intervals $(15,30$, and $60 \mathrm{~min})$. The (-) control corresponds to the mutated ACP domain.

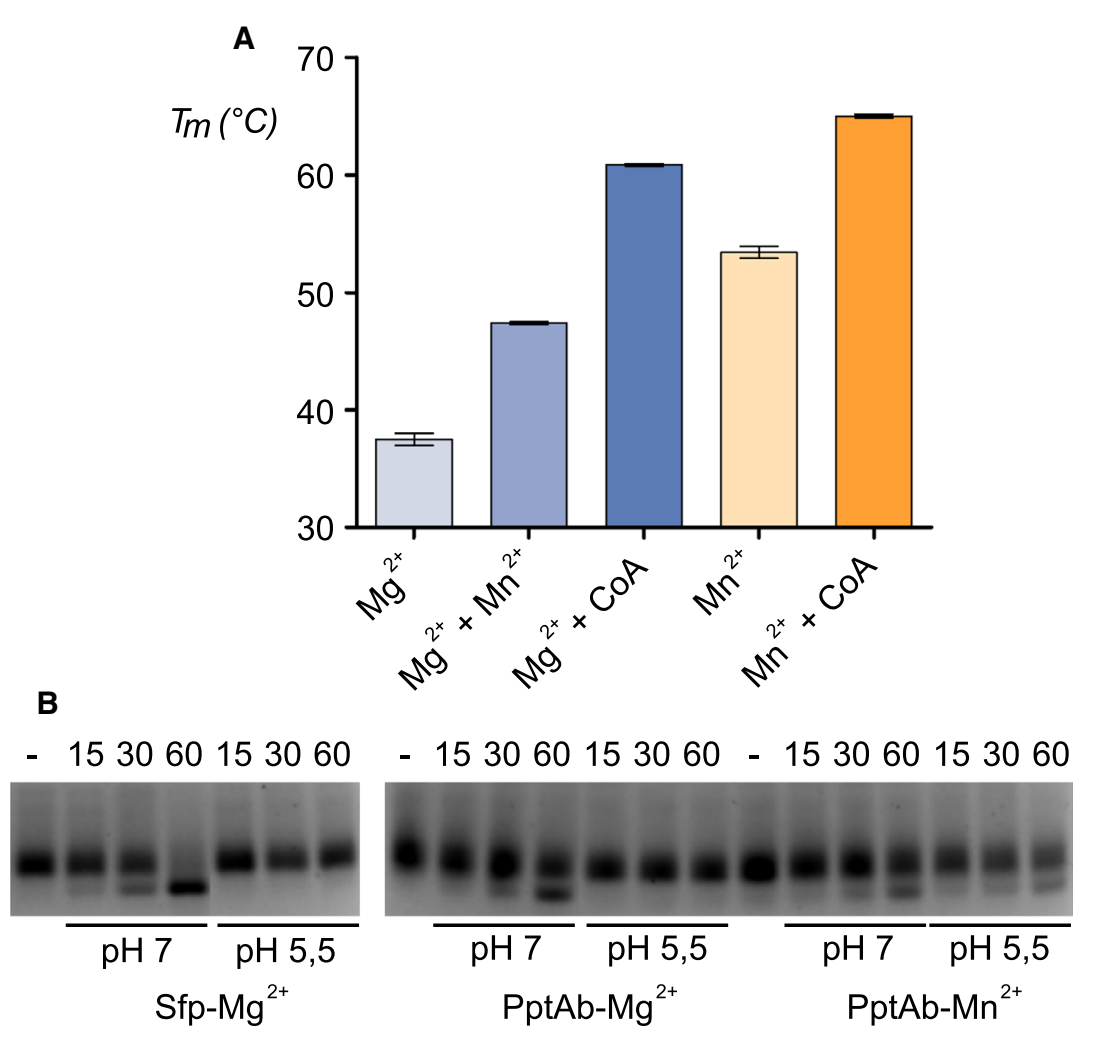

the hydroxyl group Ser2105 followed by a nucleophilic attack on the $\beta$-phosphate of CoA (Fig. 6C). The intervention of an activated water molecule in the Ppant transfer mechanism has only been proposed for the family I PPTases [5].

\section{Structure and dynamics of the ACP domain}

To date, more than forty original structures of ACP domains from bacterial and human origins have been determined in their apo, holo, and acylated forms by NMR and X-ray crystallography. They all share a four-helix bundle with the serine acceptor located at the N-terminal extremity of helix $\alpha 2$, also known as the recognition helix [25]. Best structural homologues to the ACP domain of PpsC in complex with PptAb correspond to free-standing CP domains solved by solution NMR or X-ray crystallography, with rmsd as low as $1.1 \AA$. Such structural similarities may illustrate the fact that the ACP domain undergoes only subtle structural changes upon binding to a dedicated PPTase.

In an attempt to validate the ACP contribution to the PptAb-ACP interface, we investigated the dynamics of the wild-type apo-ACP of PpsC in solution using NMR spectroscopy and amide nitrogen relaxation rate analyses. The backbone resonance assignment was performed using an ${ }^{15} \mathrm{~N}-{ }^{13} \mathrm{C}$ doubly labeled protein and standard triple resonance experiments. The chemical shift index profile determined from ${ }^{13} \mathrm{C}$ chemical shifts, as implemented by Shen et al. [26], is in full agreement with the positions of $\alpha$-helices identified in the X-ray structure of the PpsC ACP domain in complex with PptAb. ${ }^{15} \mathrm{~N}$ relaxation NMR parameters were analyzed through the modelfree approach [27] to determine the global isotropic molecular correlation time $\left(\tau_{\mathrm{c}}\right)$ and, for each residue, the order parameter $\left(\mathrm{S}^{2}\right)$ and the local correlation time $\left(\tau_{\mathrm{e}}\right)$ describing the motions of amide nitrogens. We measured an isotropic global correlation time $\tau_{\mathrm{c}}$ value of $8.60 \pm 0.66 \mathrm{~ns}$ at $25^{\circ} \mathrm{C}$, which is consistent with a monomeric state of the isolated ACP domain in solution. Values of the order parameter $S^{2}$ $(0.88 \pm 0.01)$ and the local correlation time $\tau_{\mathrm{e}}$ $(0.77 \pm 0.05 \mathrm{~ns})$ are in line with a compact globular structure of the ACP domain (Fig. 7A,B). The most flexible regions include loop 1, helix $\alpha 2$ that contains the serine acceptor, and to a lesser extent helix $\alpha 3$ (Figs 7A and 8). In addition to motions at the picoto nanosecond timescale, the relaxation data pointed out the presence of local conformational fluctuations at the micro- to millisecond timescale in the same regions (Figs $7 \mathrm{C}$ and 8 ). Our findings are in accordance with a recent study on the dynamics of an aryl 

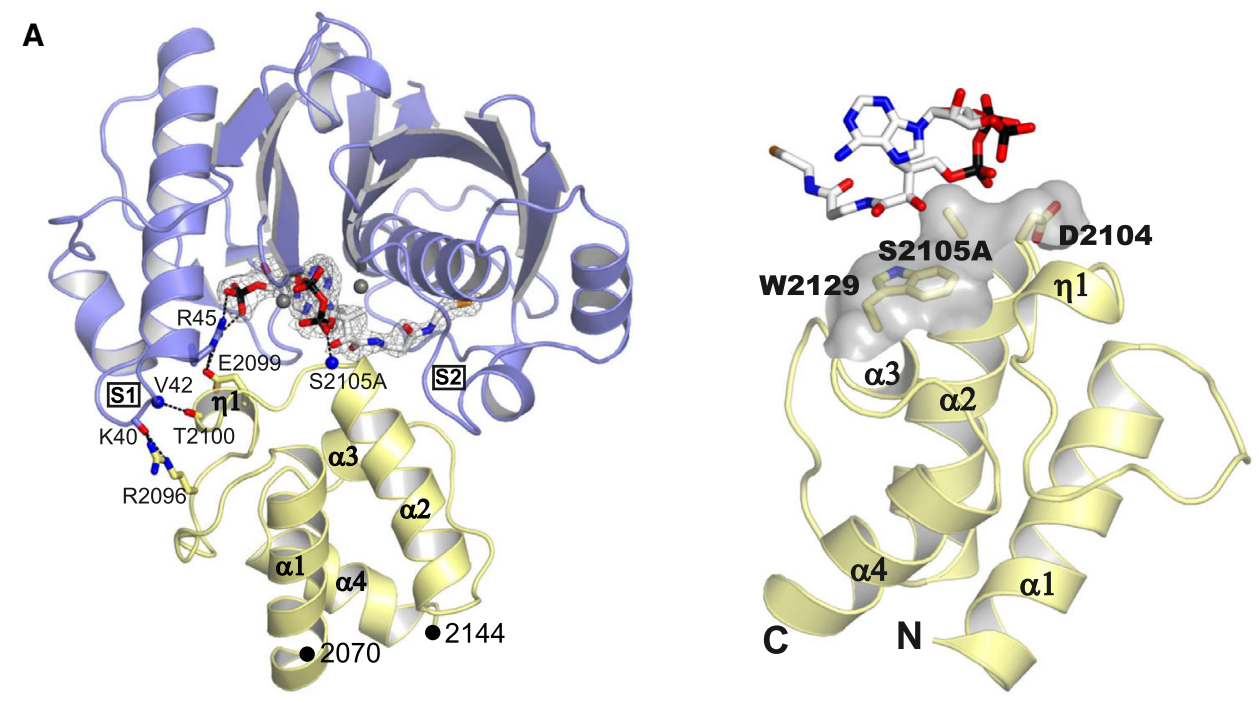

B
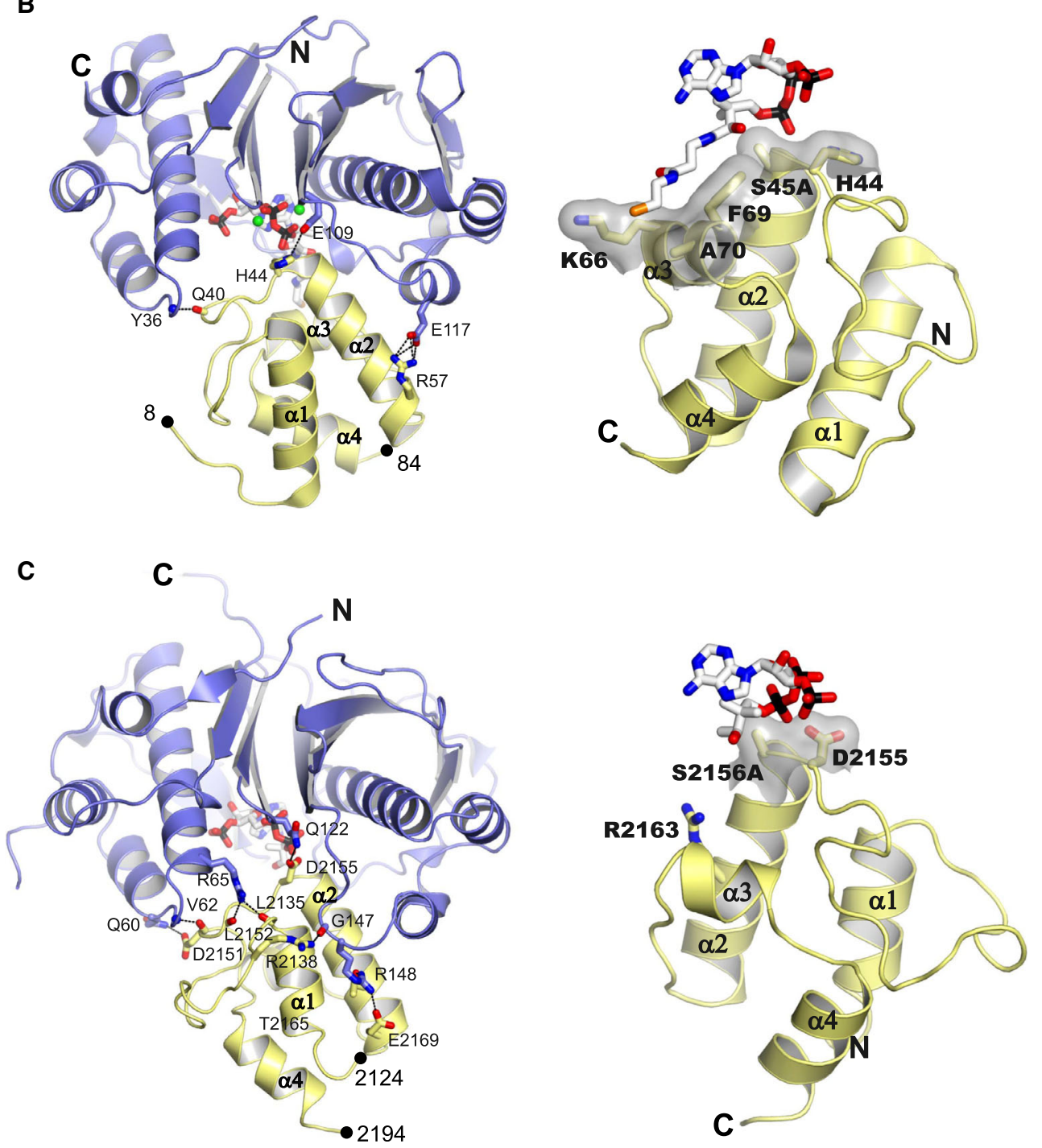
Fig. 5. Structural comparison of PPTase-CP complexes. Ribbon representation of (A) PptAb-ACP (PDB code 6RCX), (B) Sfp-PCP (PDB code 4MRT), and (C) AASDHPPT-ACP (PDB code 2CG5). PPTases and CP domains are colored in blue and yellow, respectively. Left, representation of the polar interactions at the interface. Hydrogen bond interactions are shown as dash lines in black. A SA 2Fo-Fc composite omit electron density map contoured at $1 \sigma$ around CoA are shown in black for the PptAb-ACP complex. Right, surface representation of residues of the CP domain involved in polar and nonpolar interactions with CoA [50]. The Ppant arm is not visible in the crystal structure of the AASDHPPT-ACP complex. Residues involved in polar and nonpolar interactions were identified using the PISA server [50]. Nitrogen atoms are in blue, and oxygen atoms are in red. $\mathrm{Mn}^{2+}$ and $\mathrm{Mg}^{2+}$ ions are in gray and green, respectively. All figures are in the same orientation. Figures were generated using PYMOL (The PyMOL Molecular Graphics System, version 2.0; Schrödinger, LLC).

carrier protein $(\mathrm{ArCP})$ in its apo state [28]. Larger flexibility is observed in the fast regime together with conformational fluctuations in loop 1 and to a lesser extent in the first half of helix $\alpha 2$ and the loop 2 -helix $\alpha 3$ region. In contrast, we did not observe enhanced flexibility nor larger chemical exchanges for the few residues preceding Ser2105, the site that binds the prosthetic group.

\section{Discussion}

Within an infected macrophage, bacteria are subject to numerous stresses, including local $\mathrm{pH}$ changes, nutrient limitation, and the presence of reactive nitrogen and oxygen species [29]. In this study, we asked ourselves what impact the $\mathrm{pH}$ could have on the binding of CoA and metal ions in the $4^{\prime}$-phosphopantetheinyl transferase PptAb from M. abscessus. This question is all the more relevant as many charged residues in the active site cavity of PptAb are involved in the coordination of metal ions, interactions with $\mathrm{CoA}$, and the deprotonation of the carrier protein substrate.

A remarkable feature shared by PPTases is their ability to bind endogenous CoA from the expression host. CoA sequestration was first described by Mofid et al. [30] who estimated the percentage of cellular CoA present in purified recombinant Sfp of B. subtilis at $20-30 \%$. In accordance with these observations, all the X-ray structures of PptAb examined in this study have endogenously bound $\mathrm{CoA}$ in their active site cavity, even at acidic $\mathrm{pH}$. In addition, $\mathrm{CoA}$ binding is inextricably linked to the presence of $\mathrm{Mg}^{2+}$ or $\mathrm{Mn}^{2+}$,
Fig. 6. pH-dependent modifications of CoA. (A) Close-up view of the cofactor binding cavity illustrating the structural changes for the pyrophosphate and the pantothenic acid group between PptAb alone (pH 5.5, PDB code 6QWU in white) and in complex with the ACP domain of PpsC (pH 6.5, PDB code 6RCX in gray). The structure of PptAb at physiological $\mathrm{pH}$ (in orange) is missing the Ppant moiety. A surface representation of residues that accommodate the pantothenic portion of CoA is shown. (B) A water molecule (in red) replaces the excluded $\beta$ phosphate of CoA in the PptAb-ACP complex. (C) Proposed models for the priming reaction mechanism. The metalbound glutamate side chain abstracts the hydrogen from Ser2105 (step 1), thereby initiating the Ppant transfer reaction (steps 2 and 3). In model 2, an activated metalbound water molecule deprotonates the hydroxyl group of Ser2105 (step 1'). The same color code is used for carbon atoms of $\mathrm{CoA}$, protein side chains, and divalent cations at sites I and II in panels (A) and (B). Structure figures were generated using PYMOL (The PyMOL Molecular Graphics System, version 2.0; Schrödinger, LLC).
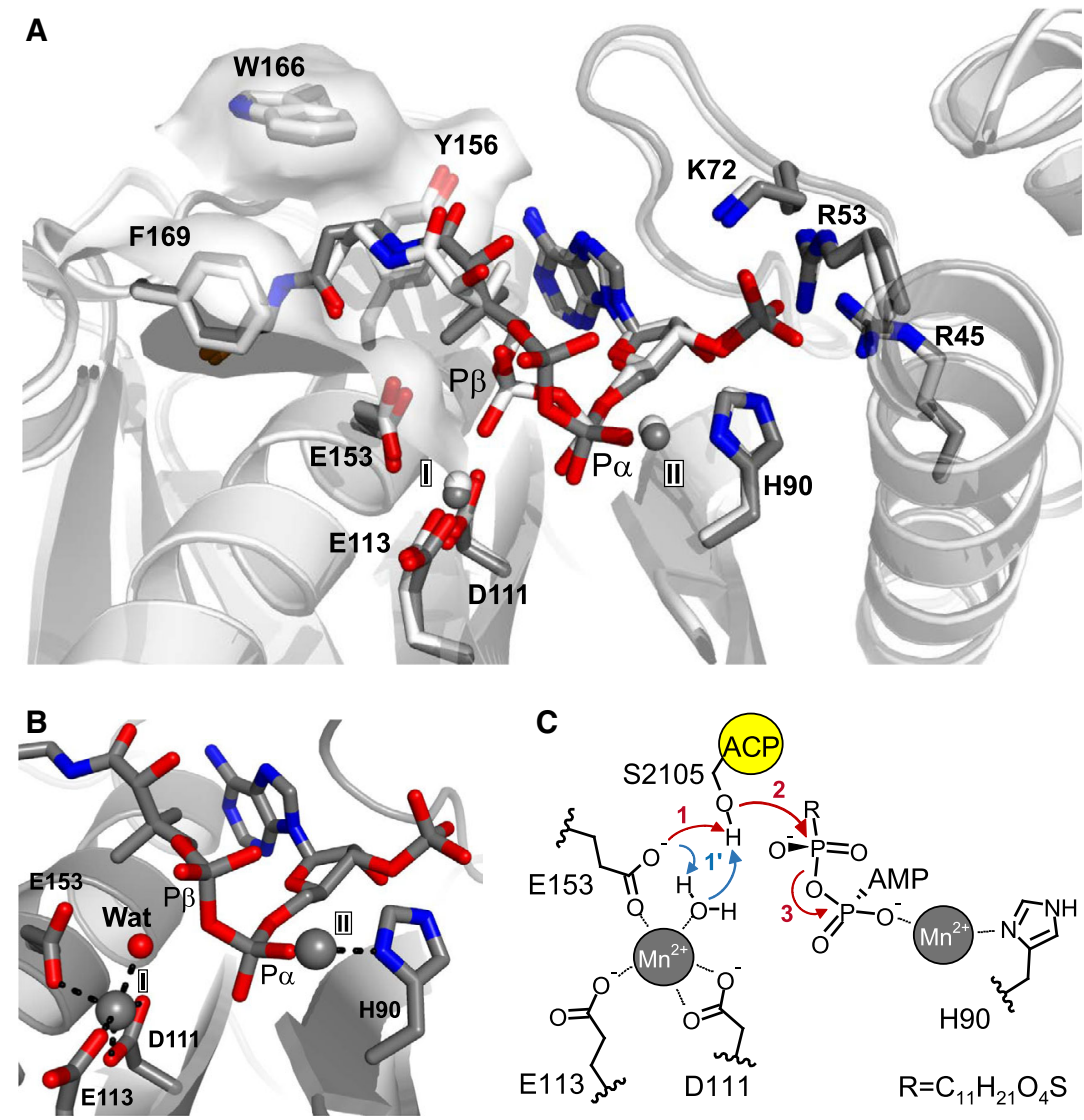
which play a key role in the transfer of the Ppant moiety on the serine acceptor of a carrier protein domain. The increased stability of PptAb in the presence of $\mathrm{Mn}^{2+}$ may be attributed to an additional metal binding site (site II) that coordinates to the $\alpha$-phosphate of CoA (Fig. 1E). Cation selectivity in favor of $\mathrm{Mn}^{2+}$ is influenced by the side chains involved in the metal coordination sphere. Indeed, it is known that $\mathrm{Mg}^{2+}$ and $\mathrm{Mn}^{2+}$ ions share aspartic acid and glutamic acid as their two major binders [31]. Histidine completes the list of major binders to $\mathrm{Mn}^{2+}$, while this amino acid residue is among the least frequently identified $\mathrm{Mg}^{2+}$ coordinators [31]. This is in agreement with the presence of $\mathrm{Mn}^{2+}$ coordinated to the imidazole group of His90 in site II. Site I plays a key role in PPTase activity as its coordination sphere involves the catalytic Glu153 in charge of initiating the Ppant transfer reaction. Questions regarding the mechanism of metal ion regulation inside cells remain unanswered. In vivo, it has been postulated that $\mathrm{Mg}^{2+}$ and $\mathrm{Mn}^{2+}$ restriction may be an additional stress encountered by intraphagosomal pathogens including M. tuberculosis [32-34].

The current picture of a Ppant moiety that either extends into a deep hydrophobic pocket, as seen with the mycobacterial enzymes PptT and MuPPT [16] and the human AASDHPPT [18], or points outside the cavity, as it is the case in the B. subtilis Sfp [17], may be biased by the acidity of the crystallization conditions. From a biological perspective, mycobacterial species such as Mycobacterium smegmatis and Mycobacterium bovis BCG are capable of maintaining an internal $\mathrm{pH}$ between 6.1 and 7.2 in response to an acidic environment [35]. When examining the effect of $\mathrm{pH}$ on the X-ray structure of PptAb, we realized that the $3^{\prime}, 5^{\prime}$-ADP moiety plays a key role in maintaining $\mathrm{CoA}$ into the cavity, thanks to a large number of hydrophobic and polar interactions with main-chain and side-chain atoms of the PPTase (Fig. 1A). The importance of the $3^{\prime}$-phosphate group was previously demonstrated for Sfp as no modification of the apoACP was detected in the presence of $3^{\prime}$-dephosphoCoA [36]. On the other hand, mutations of the two conserved arginine residues that make specific interactions with the 3'-phosphate for both PptT [16] and the human AASDHPPT [18] slightly decrease the affinity for CoA, but have a limited effect on their activity.

Upon formation of the PptAb-ACP complex, the conformation of PptAb residues involved in cofactor binding remains mostly identical (Fig. 6). Anchoring segments S1 and S2 of PptAb are the major actors in the recognition process as they concentrate the majority of polar and van der Waals interactions (Fig. 5A).
Their respective counterparts in the ACP structure include residues from loop 1 and helix $\alpha 2$. We showed from NMR relaxation data that ACP regions, which will face S1 and S2 in the complex, exhibit the largest conformational fluctuations at sub-nanosecond and micro- to millisecond timescales (Figs 7 and 8, Fig. S3). Evidences for a local reorganization of loops and helices in the ACP domain upon complex formation reinforce the idea that such internal dynamics may be key to the ACP activation step and subsequent ACP-partner interactions. The most unpredictable result came from the sequestration of the $\mathrm{CoA}$ in an unexpected conformation illustrated by an inversion of configuration at the pyrophosphate oxygen (Fig. 6). As a consequence, a water molecule at site I replaces the excluded $\beta$-phosphate of CoA and may serve as an intermediate for the Ppant transfer reaction. The resulting $\mathrm{Mn}^{2+}$ coordination sphere is different from that described in the Sfp-PCP [17] and the human AASDHPPT-ACP [18] structures, as the pyrophosphate is not within coordinating distance of the divalent cation $(3.9 \AA)$. Our structure may reflect a snapshot of a trapped Ppant transfer intermediate marked by a pyrophosphate group free of interactions with the PPTase. Taken together with previous data available on the role of specific residues implicated in PPTase activity and the recent discovery of a druglike compound that kills M. tuberculosis by partially inhibiting PptT [21], our in-depth structural analysis of PptAb from M. abscessus alone and in complex with a mycobacterial ACP domain should be beneficial for rational drug design and the development of therapeutic alternatives to treat patients with mycobacterial infections.

\section{Materials and methods}

\section{Cloning of PptAb and ACP constructs}

The gene encoding PptAb was cloned in a pET26b vector (Novagen, Madison, WI, USA) under the dependence of an IPTG-inducible T7 phage promoter. The resulting plasmid was introduced into chemically competent E. coli BL21(DE3) cells (Invitrogen, Carlsbad, CA, USA) to overproduce $\mathrm{PptAb}$ fused with a $\mathrm{C}$-terminal 6-histidine tag. The fragment encoding the ACP domain (positions 2057-2145) was PCR amplified using $p p s C$ as a DNA template and gene-specific forward 5'-GATATACATATGGCGATT CGCGCTCAGCTAGACG- $3^{\prime}$ and reverse $5^{\prime}$-AATTCACTAGTCATTCGTTCGCACAGGGCGGTCG-3' primers with NdeI and SpeI restriction sites in bold. The digested product was then inserted into commercially available pET28 vectors (Novagen) with a N-terminal 6-histidine tag. 


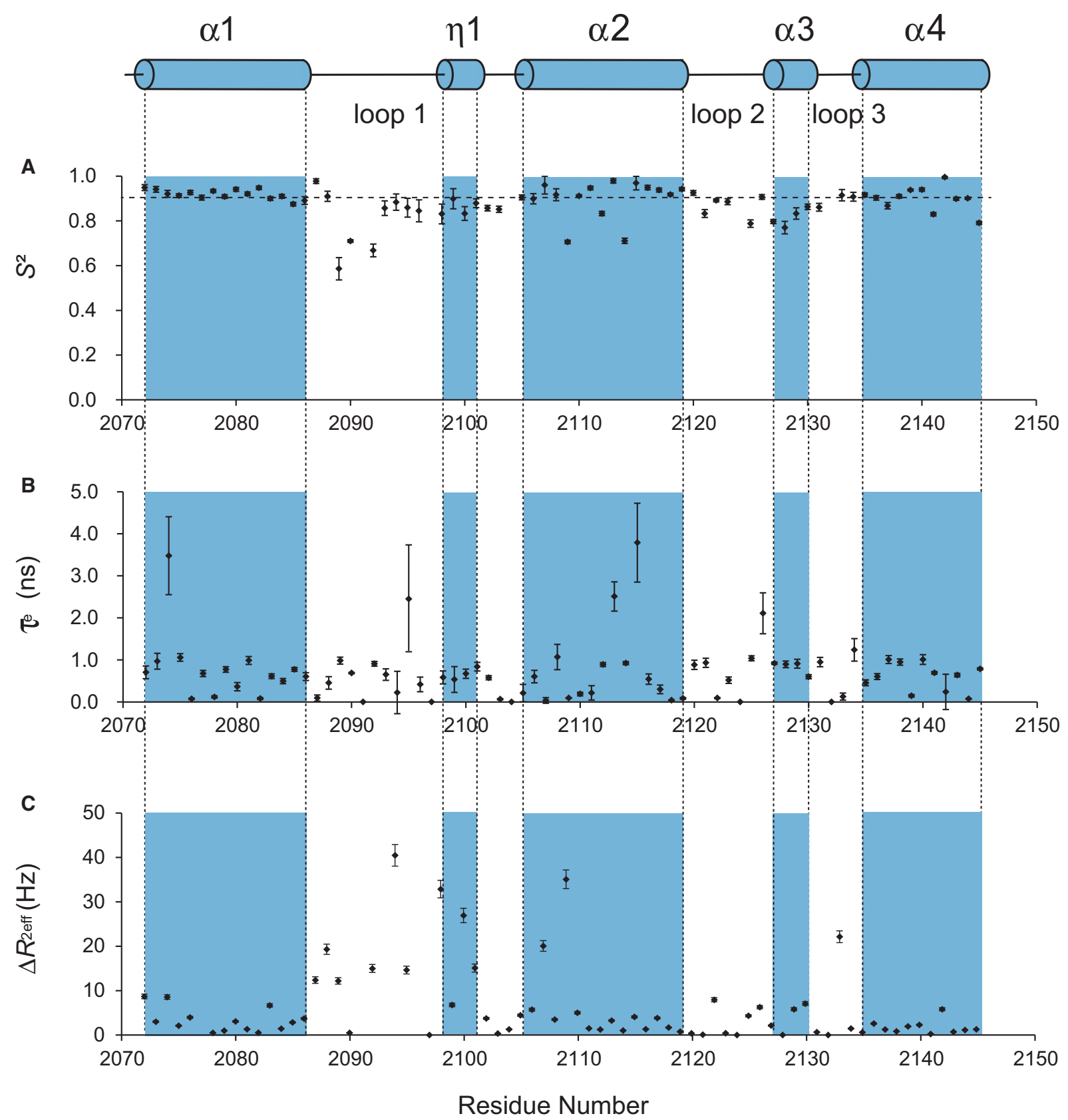

Fig. 7. ${ }^{15} \mathrm{~N}$ relaxation analysis of apo-ACP. $\mathrm{T}_{1}, \mathrm{~T}_{2}$, and $\left\{{ }^{1} \mathrm{H}\right\}-{ }^{15} \mathrm{~N}$ NOEs were acquired at two static magnetic fields $(600$ and $700 \mathrm{MHz})$. Relaxation data were then analyzed through the model-free approach to determine (A) the order parameter $S^{2}$, (B) the local correlation time

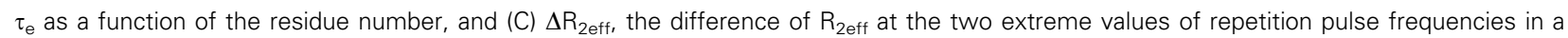
CMPG pulse train (i.e., $33 \mathrm{~Hz}$ and $1 \mathrm{kHz}$ ). Error bars correspond to $95 \%$ confidence interval, $n=2$.

Ligated plasmids were transformed into chemically competent E. coli BL21(DE3) ent $D^{-}$cells. This cell strain is a derivative from the classical BL21(DE3), with the gene coding for EntD, an endogenous PPTase in E. coli, being knocked out. Transformed cells expressing ACP and PptAb were plated onto Luria-Bertani (LB) agar plates containing $35 \mu \mathrm{g} \cdot \mathrm{mL}^{-1}$ kanamycin for overnight growth at $37^{\circ} \mathrm{C}$. The selected clones were grown in 5-mL culture containing $35 \mu \mathrm{g} \cdot \mathrm{mL}^{-1}$ kanamycin. DNA was sequenced by Eurofins (Konstanz, Germany). The S2105A ACP fragment was created by reassembly PCR using sense and antisense primers 5'-ACCCTGGGACTCGACGCGCTGATGGGCCTGGAA TTGCGC- $3^{\prime}$ and 5'-TTCCAGGCCCATCAGCGCGTCGAGTCCCAGGGTTTCCAG-3' that bear the mutation 


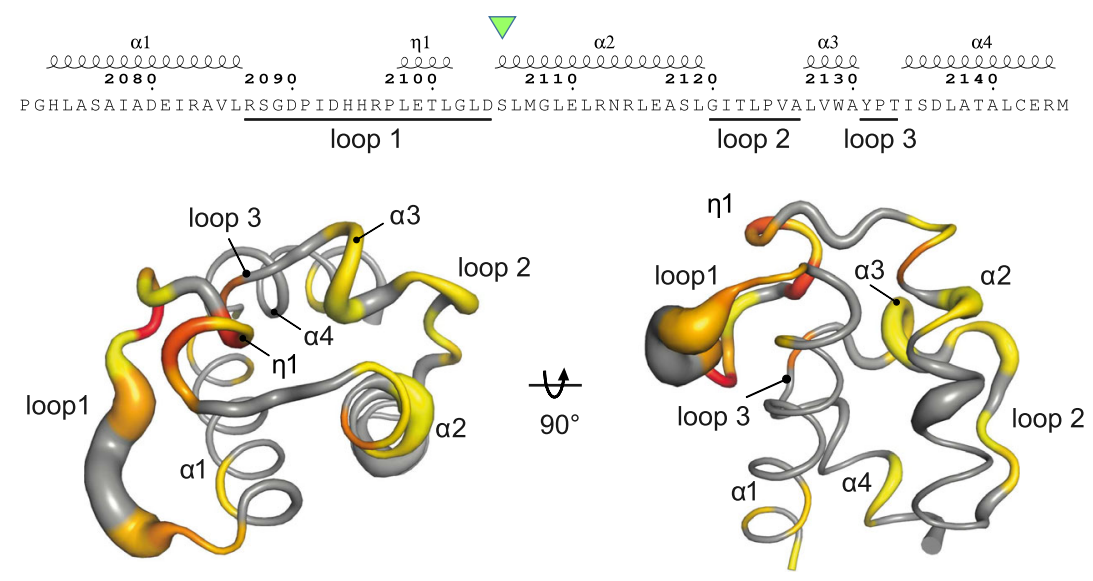

Fig. 8. Dynamics of apo-ACP. Order parameters of backbone amide nitrogen were determined from ${ }^{15} \mathrm{~N}$ relaxation studies at 600 and $700 \mathrm{MHz}$ on apo-ACP at pH 6.5 and $25^{\circ} \mathrm{C}$ and reported on the structure of ACP in complex with PptAb. Order parameters are illustrated by the tube thickness according to $\left(1-S^{2}\right)$ value, the thickness is therefore correlated flexibly at sub-nanosecond timescale. Residues prone to conformational fluctuation at intermediate timescale ( $\mu \mathrm{s}-\mathrm{ms})$ are colored from yellow to red as function of $\Delta \mathrm{R}_{2 \text { eff }}$ value $\left(v_{\mathrm{CMPG}} 33 \mathrm{~Hz}-1 \mathrm{kHz}\right)$ above $5.0 \mathrm{~Hz} . \mathrm{S}^{2}$ and $\Delta \mathrm{R}_{\text {2eff }}$ values were reported from Fig. 6. The ACP structure was generated using PYMOL (The PyMOL Molecular Graphics System, version 2.0; Schrödinger, LLC).

(in bold). Introduction of the point mutation was confirmed by conventional Sanger sequencing.

\section{Production and purification of PptAb and the ACP domain}

Frozen cells expressing the full-length PptAb were used to start an overnight $10 \mathrm{~mL}$ LB-kanamycin $\left(35 \mu \mathrm{g} \cdot \mathrm{mL}^{-1}\right)$ culture at $37^{\circ} \mathrm{C}$ prior to inoculation in baffled flasks containing $3 \mathrm{~L}$ of the same media. Cells were allowed to grow for approximately $2 \mathrm{~h}$ at $37^{\circ} \mathrm{C}$ before temperature was dropped from $37{ }^{\circ} \mathrm{C}$ to $30^{\circ} \mathrm{C}$. When $\mathrm{OD}_{600}$ reached $0.5-$ 0.7 , cells were induced with IPTG at a final concentration of $0.5 \mathrm{~mm}$ and grown for an additional $4 \mathrm{~h}$ prior to harvesting by centrifugation at $4000 \mathrm{~g}$ for $30 \mathrm{~min}$. To eliminate residual $\mathrm{LB}$ medium, the cell pellets were resuspended in $50 \mathrm{~mL}$ of $100 \mathrm{~mm}$ Tris $/ \mathrm{HCl}, \mathrm{pH} 7$, and $150 \mathrm{~mm} \mathrm{NaCl}$ prior to centrifugation at $4000 \mathrm{~g}$ for $20 \mathrm{~min}$ and storage at $-80{ }^{\circ} \mathrm{C}$. The pelleted cells were resuspended in $30 \mathrm{~mL}$ buffer $\mathrm{A}$ with either $\mathrm{MgCl}_{2}$ or $\mathrm{MnCl}_{2}$ at a final concentration of 5 and $1 \mathrm{~mm}$, respectively. After sonication (6 cycles of 30 -s pulse, $50 \%$ amplitude, and power $5 \mathrm{~W}$ ) and centrifugation at $30000 \mathrm{~g}$ for $30 \mathrm{~min}$, the lysate was loaded on a gravity-flow column with $2 \mathrm{~mL}$ of TALON $^{\circledR}$ Superflow Metal Affinity Resin (GE Healthcare, Uppsala, Sweden). The His-tagged PptAb was eluted from the column with the same buffer supplemented with $200 \mathrm{~mm}$ imidazole. The 3-mL protein elution was then injected into a HiLoad 16/ 60 Superdex 75 (GE Healthcare, Pittsburgh, PA, USA) preequilibrated with $50 \mathrm{~mm}$ Tris $/ \mathrm{HCl}, \mathrm{pH} 7,50 \mathrm{~mm} \mathrm{NaCl}$, and either $5 \mathrm{~mm} \mathrm{MgCl}_{2}$ or $1 \mathrm{~mm} \mathrm{MnCl}_{2}$.

The production of the wild-type and S2105A mutant of the ACP fragment follows the same protocol as for PptAb, except that only one purification step using affinity chromatography was implemented. The eluted protein was dialyzed against a large excess of buffer $(50 \mathrm{~mm}$ Tris $/ \mathrm{HCl}, \mathrm{pH}$ 7 , and $50 \mathrm{~mm} \mathrm{NaCl}$ ) using a semipermeable Spectra/Por ${ }^{\circledR} 3$ Dialysis Membrane (Spectrum Laboratories, Inc., Rancho Dominguez, CA, USA).

\section{DSF experiments}

Fluorescence of the SYPRO Orange Protein Gel Stain (Invitrogen) was measured using the CFX96 Real-Time PCR Detection System (Bio-Rad, Hercules, CA, USA) from $18{ }^{\circ} \mathrm{C}$ to $80{ }^{\circ} \mathrm{C}$ in $0.3{ }^{\circ} \mathrm{C}$ increments of $3 \mathrm{~s}$. PptAb was concentrated to 56 and $380 \mu \mathrm{M}$ in the presence of buffer A $(50 \mathrm{~mm}$ Tris/ $\mathrm{HCl}, \mathrm{pH} 7.0,50 \mathrm{~mm} \mathrm{NaCl}$, and $5 \mathrm{~mm}$ $\left.\mathrm{MgCl}_{2}\right)$ and buffer B (50 mM Tris/ $\mathrm{HCl}, \mathrm{pH} 7.0,50 \mathrm{~mm}$ $\mathrm{NaCl}$, and $1 \mathrm{~mm} \mathrm{MnCl}_{2}$ ), respectively. Each protein sample was then diluted to $6 \mu \mathrm{M}$. Twenty microlitre of mixtures containing $17 \mu \mathrm{L}$ PptAb $6 \mu \mathrm{M}$ and $2 \mu \mathrm{L}$ SYPRO Orange $100 \times$ was placed in 96-well clear-bottom Hard-Shell 96Well Skirted PCR Plates, Low-Profile (Bio-Rad). Addition of $1 \mu \mathrm{L}$ of a solution of buffer A, buffer $\mathrm{B}, 20 \mathrm{~mm} \mathrm{MnCl}_{2}$, or $20 \mathrm{~mm} \mathrm{CoA}$ completes the reaction mixture. Each condition was realized in triplicate. Melting temperatures were then calculated using the BIO-RAD CFX MANAGER software (Bio-Rad Laboratories, Irvine, CA, USA).

\section{Activity assays}

Activity assays were performed as previously described [23]. Briefly, PptAb at $20 \mathrm{~nm}$ was incubated at $30{ }^{\circ} \mathrm{C}$ with $10 \mu \mathrm{M}$ of ACP domain of PpsC, $50 \mu \mathrm{M} \mathrm{CoA}$, and $10 \mathrm{~mm}$ DTT. $\mathrm{MnCl}_{2}$ or $\mathrm{MgCl}_{2}$ at $1 \mathrm{~mm}$ final concentration was also 
present in the reaction mixture. Reaction was stopped at different times with the addition of $100 \mathrm{~mm}$ EDTA. A positive control was included using the broad-spectrum PPTase Sfp from B. subtilis at the same concentration. Samples were then loaded on a $10 \%$ polyacrylamide gel supplemented with $2.5 \mathrm{~m}$ urea and revealed with Coomassie blue.

\section{NMR spectroscopy experiments}

Frozen cells expressing PpsC ACP domain from a pET28 vector were used to start three overnight cultures of $5 \mathrm{~mL}$ LB-kanamycin $\left(35 \mu \mathrm{g} \cdot \mathrm{mL}^{-1}\right)$ at $37^{\circ} \mathrm{C}$. Following centrifugation at $5000 \mathrm{~g}$ for $5 \mathrm{~min}$, cells were resuspended in a total volume of $10 \mathrm{~mL}$ M9 medium supplemented with kanamycin $\left(35 \mu \mathrm{g} \cdot \mathrm{mL}^{-1}\right)$ prior to inoculation in $2 \mathrm{~L}$ M9 medium. Production and purification follow the same protocol as for ACP in LB medium. The purified protein was dialyzed against a large excess of buffer $\left(50 \mathrm{~mm} \mathrm{KHPO}_{4}\right.$, $\mathrm{pH}$ 6.5, and $100 \mathrm{~mm} \mathrm{NaCl}$ ) using a semipermeable Spectra/ Por $^{\circledR} 3$ Dialysis Membrane (Spectrum Laboratories, Inc.). NMR sample consisted of $550 \mu \mathrm{M}\left[{ }^{13} \mathrm{C},{ }^{15} \mathrm{~N}\right]$-ACP supplemented with $10 \mu \mathrm{M}$ 2,2-dimethyl-2-silapentane-5-sulfonate (DSS) in $\mathrm{H}_{2} \mathrm{O} / \mathrm{D}_{2} \mathrm{O}(9: 1)$. NMR experiments were performed at $23{ }^{\circ} \mathrm{C}$ on 600 and $700 \mathrm{MHz}$ Bruker Avance III HD spectrometers (Bruker, France). The sequential backbone resonance assignments were performed using the best version of $\mathrm{HNCACB}, \mathrm{HN}(\mathrm{CO}) \mathrm{CACB}$, and $\mathrm{HNCO}$ experiments [38] with selective ${ }^{1} \mathrm{H}$ pulses centered at 8.5 p.p.m., covering a bandwidth of 4.0 p.p.m., and a standard $\mathrm{HN}$ (CA)CO experiment. Proton and carbon aliphatic sidechain assignments were obtained by analyzing $(\mathrm{H}) \mathrm{CC}(\mathrm{CO})$ $\mathrm{NH}$ and $\mathrm{H}(\mathrm{CC})(\mathrm{CO}) \mathrm{NH}$ total correlation spectroscopy $\left({ }^{13} \mathrm{C}-{ }^{13} \mathrm{C}\right.$ TOCSY with 11 and $20 \mathrm{~ms}$ mixing times). All residues were assigned except the serine acceptor Ser2105, which was not detectable. Backbone torsion angles were predicted from carbon chemical shifts using TALOS + [26]. Secondary structure elements matched the structure of ACP (S2105A) in complex with PptAb elucidated by X-ray crystallography. $\mathrm{T}_{1}$ and $\mathrm{T}_{2}{ }^{15} \mathrm{~N}$ relaxation experiments were performed using standard experiments with relaxation delays of 10, 100, 200 (duplicated), 300, 400, 600, 800 (duplicated), 1000, 1200, and $1500 \mathrm{~ms}$ and $0,16.9,33.9$ (duplicated), 50.9, 67.8, 101.7, 135.7, 169.6, and $237.4 \mathrm{~ms}$ for $\mathrm{T}_{1}$ and $\mathrm{T}_{2}$, respectively. Carr-Purcell-Meiboom-Gill train pulses were applied at $3.125 \mathrm{kHz}{ }^{15} \mathrm{~N}$ RF field strength with an inter $\pi$ pulse delay of $900 \mu \mathrm{s}$. $\left\{{ }^{1} \mathrm{H}\right\}-{ }^{15} \mathrm{~N}$ heteronuclear NOE data were obtained using a ${ }^{1} \mathrm{H}$ saturation train pulse of $3 \mathrm{~s}$ (pulse flip angle $120^{\circ}$ at $20.8 \mathrm{KHz} \mathrm{RF}$ field strength, with an interpulse delay of $5 \mathrm{~ms}$ ) with a global recycling delay of $5 \mathrm{~s} . \mathrm{T}_{1}, \mathrm{~T}_{2}$, and $\left\{{ }^{1} \mathrm{H}\right\}-{ }^{15} \mathrm{~N}$ heteronuclear NOE described above were acquired at two distinct static magnetic fields (i.e., 600 and $700 \mathrm{MHz}$ spectrometer). $\mathrm{T}_{2}$ relaxation dispersion experiments were performed as previously described [39] with a 30-ms CPMG train pulse and the following $v_{\text {CPMG }}$ repetition rates: 0 (duplicated), 33,
67, 100, 133, 167, 233, 267 (duplicated), 333, 400, 533, 600, 633, 700, 733, 800, 900, 967, and 1000 Hz. Duplicated datasets were used to estimate uncertainties for the peak intensity. The NMR spectra were processed with TOPSPIN 3.5 software (Bruker Biospin), and assignments were performed using CARA software [40]. ${ }^{15} \mathrm{~N}$ relaxation data were analyzed using the Dynamics Center software from Bruker Biospin. $\mathrm{R}_{1}, \mathrm{R}_{2}$ relaxation rates and $\left\{{ }^{1} \mathrm{H}\right\}-{ }^{15} \mathrm{~N}$ NOEs were determined from peak intensities. The molecular rotational correlation time of $\mathrm{PpsC} \mathrm{ACP}$ at $23{ }^{\circ} \mathrm{C}$ was calculated from the $T_{1} / T_{2}$ ratio on 33 residues, excluding residues that do have fast local motion with $\left\{{ }^{1} \mathrm{H}\right\}-{ }^{15} \mathrm{~N}$ NOEs $<0.65$ and residues with an exchange contribution to $\mathrm{R}_{2} \quad\left(\mathrm{R}_{\mathrm{ex}}\right) \quad$ (typically when $\left(\left(\mathrm{T}_{2}-<\mathrm{T}_{2}>\right) / \mathrm{T}_{2}\right) /$ $\left.\left(\left(\mathrm{T}_{1}-<\mathrm{T}_{1}>\right) / \mathrm{T}_{1}\right)>3\right)$. In these conditions, the average $\tau_{\mathrm{c}}$ was estimated at $8.60 \pm 0.66 \mathrm{~ns}$, which is in line with a monomeric form of ACP at $23{ }^{\circ} \mathrm{C}$ [41]. The order parameter and its correlation time $\tau_{\mathrm{e}}$ was determined from the fit of

$$
\begin{aligned}
J_{(\omega)}= & \frac{2}{5} \\
& \times \tau_{\mathrm{c}}\left[\frac{S^{2}}{\left(1+\left(\tau_{\mathrm{c}} \cdot \omega\right)^{2}\right)}+\frac{\left(1-S^{2}\right) \times\left(\tau_{\mathrm{c}}+\tau_{\mathrm{e}}\right) \times \tau_{\mathrm{e}}}{\left(\tau_{\mathrm{c}}+\tau_{\mathrm{e}}\right)^{2}+\left(\omega \times \tau_{\mathrm{c}} \times \tau_{\mathrm{e}}\right)^{2}}\right],
\end{aligned}
$$

on experimental $\mathrm{R}_{1}, \mathrm{R}_{2}$, and $\left\{{ }^{1} \mathrm{H}\right\}-{ }^{15} \mathrm{~N}$ NOEs at two static fields (i.e., 600 and $700 \mathrm{MHz}$ ), a fit was also performed with the same model plus an additional term, $\mathrm{R}_{\mathrm{ex}}$, to account for the contribution of $\mathrm{R}_{\mathrm{ex}}$ on $\mathrm{R}_{2}$ for residues prone to chemical exchange at $\mu \mathrm{s}-\mathrm{ms}$ timescale. For each residue, the best fit was taken considering the $T_{1} / T_{2}$ ratio and deviations of backcalculated relaxation parameters, in particular the transverse relaxation rate $R_{2}$.

\section{Crystallization and structure determination of PptAb}

PptAb purified in the presence of $\mathrm{MgCl}_{2} / \mathrm{CoA}$ or $\mathrm{MnCl}_{2}$ was concentrated to 5 and $10 \mathrm{mg} \cdot \mathrm{mL}^{-1}$ and mixed in a $1: 1$ volume ratio using screening conditions kits from Qiagen (Venlo, the Netherlands). MRC 2-well crystallization plates (Hampton Research, Aliso Viejo, CA, USA) were filled using a Mosquito crystallization robot (SPT Labtech, Melbourn, UK) and imaged using a Rock Imager 1000 (Formulatrix, Bedford, MA, USA). Well-diffracting crystals could be obtained in many different conditions that are listed in Table 1. Crystals were flash-frozen in liquid nitrogen. Datasets were collected at the European Synchrotron Radiation Facility (Grenoble, France) and ALBA (Barcelona, Spain), and processed using the XDS program package (Table 2). Structures were solved by molecular replacement using the X-ray structure of PptT (PDB code 4U89) as a template in PHASER [42]. Iterative cycles of 
manual model building in СоОт [43] and refinement procedures using PHENIX refine [44] were applied until convergence. Surface electrostatic potential maps were calculated using APBS and PDB2PQR programs [45]. PDB2PQR was used to generate the input files for the APBS program utilizing the PARSE force field, and PROPKA to assign protonation states at different $\mathrm{pH}$ values $[46,47]$. Blue shading $\left(+5 k_{\mathrm{B}} T / e\right)$ indicates electropositive protein surface, and red shading $\left(-5 k_{\mathrm{B}} T / e\right)$ indicates electronegative protein surface. All structures and the electrostatic potential of protein surfaces were visualized with PYMOL (The PyMOL Molecular Graphics System, version 1.8.4.0; Schrödinger, LLC). Atomic coordinates have been deposited in the Protein Data Bank under the accession codes 6QWU (PptAb, $\left.\mathrm{CoA}, \mathrm{Mn}^{2+}, \mathrm{pH} 5.5\right)$, 6QXQ (PptAb, CoA, $\mathrm{Mn}^{2+}, \mathrm{pH}$ 7), 6QXR (PptAb, CoA, $\mathrm{Mn}^{2+}$, pH 8.5), 6QYF (PptAb, CoA, $\mathrm{Mg}^{2+}, \mathrm{pH}$ 4.6), 6QYG (PptAb, CoA, $\mathrm{Mg}^{2+}, \mathrm{pH} 8.5$ ), and 6RCX (PptAb-ACP, CoA, $\mathrm{Mn}^{2+}, \mathrm{pH}$ 6.5). Significant anomalous signal was detected for $\mathrm{Mn}^{2+}$ ions (Fig. S4).

\section{Crystallization and structure determination of the PptAb-ACP complex}

The two partner proteins were mixed together in buffer (50 mm Tris, $\mathrm{pH} \mathrm{7,} 50 \mathrm{~mm} \mathrm{NaCl}, 2 \mathrm{~mm} \mathrm{CoA}$, and $10 \mathrm{~mm}$ $\mathrm{MgCl}_{2}$ ) in $1: 1$ molar ratio at a final concentration of $400 \mu \mathrm{M}$. The mixture was incubated on ice for $2 \mathrm{~h}$ prior to crystallization trials. Diffraction-quality crystals were grown by the vapor diffusion technique at $12{ }^{\circ} \mathrm{C}$. A $4-\mu \mathrm{L}$ (1:1 protein/reservoir solution) drop was equilibrated in $400 \mu \mathrm{L}$ reservoir solution containing $0.1 \mathrm{~m} \mathrm{Na}$ cacodylate, $\mathrm{pH} 6.5,30 \%$ (w/v) PEG 8K, and $0.2 \mathrm{~m}(\mathrm{NH} 4)_{2} \mathrm{SO}_{4}$. Platelike crystals were flash-frozen in liquid nitrogen. Datasets were collected at the beamline ID29 of the European Synchrotron Radiation Facility (Grenoble, France) and processed using the XDS program package [48] (Table 2). Structures were solved by molecular replacement using the X-ray structures of PptT (PDB code 4U89) and the PCP domain from B. subtilis (PDB code 4MRT) as templates in PHASER [42]. Iterative cycles of manual model building in COOT [43] and refinement procedures using PHENIX refine [44] were applied until convergence. The final PptAb and ACP models comprise amino acids 4-219 and 2070-2145, respectively.

\section{Acknowledgements}

This work was supported by the European project Eurostars (CombiBio grant 10559) and Agence Nationale de la Recherche (PPTases, grant ANR-16-CE180011-01), the 'Vaincre la Mucoviscidose' Association (grants RF20140501019 and RF20160501623) and the French Ministry of Europe and Foreign Affairs (PhD fellowship for MCN). The equipment used for DSF, crystallization, and NMR experiments is part of the
Integrated Screening Platform of Toulouse (PICT, IBiSA). We thank the staff of synchrotron beamlines ID23-1, ID29, and ID30b at the European Synchrotron Radiation Facility (ESRF, Grenoble, France) and the XALOC beamline at ALBA (Barcelona, Spain).

\section{Conflict of interest}

The authors declare no conflict of interest.

\section{Author contributions}

MCN, OS, CCa, SG, SS, MPT, and J-DP performed the experiments and analyzed the data. J-DP wrote the paper with contributions from all the authors. $\mathrm{CCh}$, $\mathrm{CG}, \mathrm{LM}$, and J-DP provided funding.

\section{References}

1 Weissman KJ \& Leadlay PF (2005) Combinatorial biosynthesis of reduced polyketides. Nat Rev Microbiol 3, 925-936.

2 Forrellad MA, Klepp LI, Gioffré A, Sabio y García J, Morbidoni HR, de la Paz Santangelo M, Cataldi AA \& Bigi F (2013) Virulence factors of the Mycobacterium tuberculosis complex. Virulence 4, 3-66.

3 Griffith DE, Aksamit T, Brown-elliott BA, Catanzaro A, Daley C, Gordin F, Holland SM, Horsburgh R, Huitt G, Iademarco MF et al. (2007) An official ATS/ IDSA statement: diagnosis, treatment, and prevention of nontuberculous mycobacterial diseases. Am J Respir Crit Care Med 175, 367-416.

4 Bryant JM, Grogono DM, Rodriguez-Rincon D, Everall I, Brown KP, Moreno P, Verma D, Hill E, Drijkoningen J, Gilligan P et al. (2016) Emergence and spread of a human-transmissible multidrugresistant nontuberculous Mycobacterium. Science 354, 751-757.

5 Parris KD, Lin L, Tam A, Mathew R, Hixon J, Stahl M, Fritz CC, Seehra J \& Somers WS (2000) Crystal structures of substrate binding to Bacillus subtilis holo(acyl carrier protein) synthase reveal a novel trimeric arrangement of molecules resulting in three active sites. Structure 8, 883-895.

6 Mofid MR, Finking R, Essen LO \& Marahiel MA (2004) Structure-based mutational analysis of the 4'phosphopantetheinyl transferases Sfp from Bacillus subtilis: carrier protein recognition and reaction mechanism. Biochemistry 43, 4128-4136.

7 Beld J, Sonnenschein EC, Vickery CR, Noel JP \& Burkart MD (2014) The phosphopantetheinyl transferases: catalysis of a post-translational modification crucial for life. Nat Prod Rep 31, 61-108. 
8 Fichtlscherer F, Wellein C, Mittag M \& Schweizer E (2000) A novel function of yeast fatty acid synthase. Eur J Biochem 267, 2666-2671.

9 Johansson P, Mulinacci B, Koestler C, Vollrath R, Oesterhelt D \& Grininger M (2009) Multimeric options for the auto-activation of the Saccharomyces cerevisiae FAS type I megasynthase. Structure 17, 1063-1074.

10 Quadri LE, Sello J, Keating TA, Weinreb PH \& Walsh CT (1998) Identification of a Mycobacterium tuberculosis gene cluster encoding the biosynthetic enzymes for assembly of the virulence-conferring siderophore mycobactin. Chem Biol 5, 631-645.

11 Chalut C, Botella L, de Sousa-D'Auria C, Houssin C \& Guilhot C (2006) The nonredundant roles of two 4'phosphopantetheinyl transferases in vital processes of Mycobacteria. Proc Natl Acad Sci USA 103, 8511-8516.

12 Zimhony O, Schwarz A, Raitses-Gurevich M, Peleg Y, Dym O, Albeck S, Burstein Y \& Shakked Z (2015) AcpM, the meromycolate extension Acyl carrier protein of Mycobacterium tuberculosis, is activated by the $4^{\prime}$ phosphopantetheinyl transferase PptT, a potential target of the multistep mycolic acid biosynthesis. Biochemistry 54, 2360-2371.

13 Ripoll F, Pasek S, Schenowitz C, Dossat C, Macheras E, Heym B, Herrmann J, Daffe M, Brosch R, Risler JL et al. (2009) Non mycobacterial virulence genes in the genome of the emerging pathogen Mycobacterium abscessus. PLoS One 4, 1-12.

14 Davidson LB, Nessar R, Kempaiah P, Perkins DJ \& Byrd TF (2011) Mycobacterium abscessus glycopeptidolipid prevents respiratory epithelial TLR2 signaling as measured by $\mathrm{H} \beta \mathrm{D} 2$ gene expression and IL-8 release. PLoS One 6, e29148.

15 Nessar R, Reyrat JM, Davidson LB \& Byrd TF (2011) Deletion of the mmpL4b gene in the Mycobacterium abscessus glycopeptidolipid biosynthetic pathway results in loss of surface colonization capability, but enhanced ability to replicate in human macrophages and stimulate their innate immune response. Microbiology 157, 1187-1195.

16 Vickery CR, Kosa NM, Casavant EP, Duan S, Noel JP \& Burkart MD (2014) Structure, biochemistry, and inhibition of essential 4'-phosphopantetheinyl transferases from two species of Mycobacteria. ACS Chem Biol 9, 1939-1944.

17 Reuter K, Mofid MR, Marahiel MA \& Ficner R (1999) Crystal structure of the surfactin synthetase-activating enzyme sfp: a prototype of the $4^{\prime}$-phosphopantetheinyl transferase superfamily. EMBO J 18, 6823-6831.

18 Bunkoczi G, Pasta S, Joshi A, Wu X, Kavanagh KL, Smith S \& Oppermann U (2007) Mechanism and substrate recognition of human holo ACP synthase. Chem Biol 14, 1243-1253.

19 Tortoli E, Fedrizzi T, Meehan CJ, Trovato A, Grottola A, Giacobazzi E, Serpini GF, Tagliazucchi S, Fabio A,
Bettua C et al. (2017) The new phylogeny of the genus Mycobacterium: the old and the news. Infect Genet Evol 56, 19-25.

20 Jung J, Bashiri G, Johnston JM, Brown AS, Ackerley DF \& Baker EN (2014) Crystal structure of the essential mycobacterium tuberculosis phosphopantetheinyl transferase PptT, solved as a fusion protein with maltose binding protein. $J$ Struct Biol 188, 274-278.

21 Ballinger E, Mosior J, Hartman T, Burns-huang K, Gold B, Morris R, Goullieux L, Blanc I, Vaubourgeix J, Lagrange $\mathrm{S}$ et al. (2019) Opposing reactions in coenzyme A metabolism sensitize Mycobacterium tuberculosis to enzyme inhibition. Science $\mathbf{3 6 3}$, eaau8959.

22 Pedelacq JD, Nguyen HB, Cabantous S, Mark BL, Listwan P, Bell C, Friedland N, Lockard M, Faille A, Mourey L et al. (2011) Experimental mapping of soluble protein domains using a hierarchical approach. Nucleic Acids Res 39, e125.

23 Rottier K, Faille A, Prudhomme T, Leblanc C, Chalut C, Cabantous S, Guilhot C, Mourey L \& Pedelacq JDJD (2013) Detection of soluble co-factor dependent protein expression in vivo: application to the $4^{\prime}$ phosphopantetheinyl transferase PptT from Mycobacterium tuberculosis. J Struct Biol 183, 320-328.

24 Tufar P, Rahighi S, Kraas FII, Kirchner DKK, Löhr F, Henrich E, Köpke J, Dikic I, Güntert P, Marahiel MAA et al. (2014) Crystal structure of a PCP/Sfp complex reveals the structural basis for carrier protein posttranslational modification. Chem Biol 21, 552-562.

25 Zhang Y-M, Marrakchi H, White SW \& Rock CO (2003) The application of computational methods to explore the diversity and structure of bacterial fatty acid synthase. $J$ Lipid Res 44, 1-10.

26 Shen Y, Delaglio F, Cornilescu G \& Bax A (2009) TALOS+: a hybrid method for predicting protein backbone torsion angles from NMR chemical shifts. $J$ Biomol NMR 44, 213-223.

27 D'Auvergne EJ \& Gooley PR (2008) Optimisation of NMR dynamic models I. Minimisation algorithms and their performance within the model-free and Brownian rotational diffusion spaces. J Biomol NMR 40,107-119.

28 Goodrich AC, Meyers DJ \& Frueh DP (2017) Molecular impact of covalent modifications on nonribosomal peptide synthetase carrier protein communication. J Biol Chem 292, 10002-10013.

29 Stallings CL \& Glickman MS (2010) Is Mycobacterium tuberculosis stressed out? A critical assessment of the genetic evidence. Microbes Infect 12, 1091-1101.

30 Mofid MR, Marahiel MA, Ficner R \& Reuter K (1999) Crystallization and preliminary crystallographic studies of Sfp: a phosphopantetheinyl transferase of modular peptide synthetases. Acta Crystallogr D 55, 1098-1100. 
31 Brylinski M \& Skolnick J (2011) FINDSITE-metal: integrating evolutionary information and machine learning for structure-based metal-binding site prediction at the proteome level. Proteins 79, 735-751.

32 Buchmeier N, Blanc-Potard A, Ehrt S, Piddington D, Riley L \& Groisman EA (2000) A parallel intraphagosomal survival strategy shared by Mycobacterium tuberculosis and Salmonella enterica. Mol Microbiol 35, 1375-1382.

33 Lavigne J, O'Callaghan D \& Blanc-Potard A-B (2005) Requirement of MgtC for Brucella suis intramacrophage growth: a potential mechanism shared by Salmonella enterica and Mycobacterium tuberculosis for adaptation to a low-Mg2+ environment. Infect Immun 73, 3160-3163.

34 Neyrolles O, Wolschendorf F, Mitra A \& Niederweis M (2015) Mycobacteria, metals, and the macrophage. Immunol Rev 264, 249-263.

35 Rao M, Streur TL, Aldwell FE \& Cook GM (2001) Intracellular $\mathrm{pH}$ regulation by Mycobacterium smegmatis and Mycobacterium bovis BCG. Microbiology 147, 1017-1024.

36 Quadri LEN, Weinreb PH, Lei M, Nakano MM, Zuber P \& Walsh CT (1998) Characterization of Sfp, a Bacillus subtilis phosphopantetheinyl transferase for peptidyl carder protein domains in peptide synthetases. Biochemistry 37, 1585-1595.

37 Lescop E, Schanda P \& Brutscher B (2007) A set of BEST triple-resonance experiments for time-optimized protein resonance assignment. J Magn Reson 187, 163169.

38 Tollinger M, Skrynnikov NR, Mulder FAA, FormanKay JD \& Kay LE (2001) Slow dynamics in folded and unfolded states of an SH3 domain. J Am Chem Soc 123, 11341-11352.

39 Keller RLJ (2004) The Computer Aided Resonance Assignment Tutorial. Goldau, Switzerland: CANTINA Verlag and Rochus Keller.

40 Kay LE, Torchia DA \& Bax A (1989) Backbone dynamics of proteins as studied by $15 \mathrm{~N}$ inverse detected heteronuclear NMR spectroscopy: application to staphylococcal nuclease. Biochemistry 28, 8972-8979.

41 McCoy AJ, Grosse-Kunstleve RW, Adams PD, Winn MD, Storoni LC \& Read RJ (2007) Phaser crystallographic software. J Appl Crystallogr 40, 658674.

42 Emsley P, Lohkamp B, Scott WG \& Cowtan K (2010) Features and development of Coot. Acta Crystallogr D 66, 486-501.

43 Adams PD, Afonine PV, Bunkóczi G, Chen VB, Davis IW, Echols N, Headd JJ, Hung L-W, Kapral GJ, Grosse-Kunstleve RW et al. (2010) PHENIX: a comprehensive Python-based system for macromolecular structure solution. Acta Crystallogr D 66, 213-221.

44 Jurrus E, Engel D, Star K, Monson K, Brandi J, Felberg LE, Brookes DH, Wilson L, Chen J, Liles K et al. (2018) Improvements to the APBS biomolecular solvation software suite. Protein Sci 27, 112-128.

45 Søndergaard CR, Olsson MHM, Rostkowski M \& Jensen JH (2011) Improved treatment of ligands and coupling effects in empirical calculation and rationalization of $\mathrm{pKa}$ values. $J$ Chem Theory Comput 7, 2284-2295.

46 Olsson MHM, Søndergaard CR, Rostkowski M \& Jensen JH (2011) PROPKA3: consistent treatment of internal and surface residues in empirical $\mathrm{p} K_{\mathrm{a}}$ predictions BT. J Chem Theory Comput 7, 525-537.

47 Kabsch W (2010) XDS. Acta Crystallogr D 66, 125132.

48 Robert X \& Gouet P (2014) Deciphering key features in protein structures with the new ENDscript server. Nucleic Acids Res 42, 320-324.

49 Krissinel E \& Henrick K (2007) Inference of macromolecular assemblies from crystalline state. $J \mathrm{Mol}$ Biol 372, 774-797.

\section{Supporting information}

Additional supporting information may be found online in the Supporting Information section at the end of the article.

Fig. S1. The $3^{\prime}, 5^{\prime}$-ADP moiety of CoA.

Fig. S2. CoA binding at physiological pH in PptAb.

Fig. S3. ACP local conformational motions spotted on the PptAb-ACP complex.

Fig. S4. The cation binding sites. 


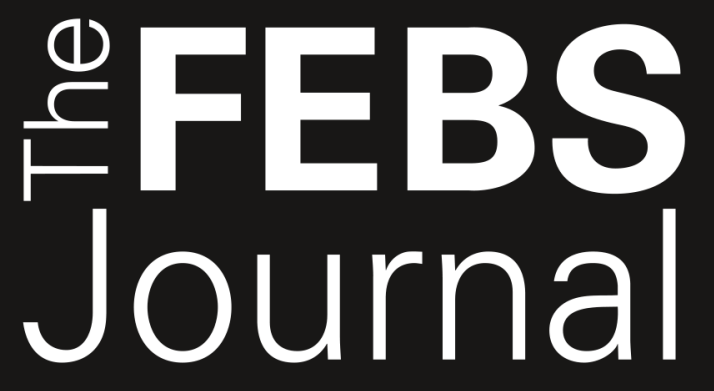

\section{Conformational flexibility of coenzyme A and its} impact on the post-translational modification of acyl carrier proteins by 4'-phosphopantetheinyl transferases

Minh Chau Nguyen, Olivier Saurel, Coralie Carivenc, Sabine Gavalda, Stéphane Saitta, Mai Phuong Tran, Alain Milon, Christian Chalut, Christophe Guilhot, Lionel Mourey and Jean-Denis Pedelacq

DOI: $10.1111 /$ febs. 15273 


\section{Conformational flexibility of coenzyme $A$ and its impact on the post-translational modification of acyl carrier proteins by 4'-phosphopantetheinyl transferases.}

Minh Chau Nguyen, Olivier Saurel, Coralie Carivenc, Sabine Gavalda, Stéphane Saitta, Mai Phuong Tran, Alain Milon, Christian Chalut, Christophe Guilhot, Lionel Mourey, and Jean-Denis Pedelacq*

Institut de Pharmacologie et de Biologie Structurale, IPBS, Université de Toulouse, CNRS, UPS, Toulouse, France.

*To whom correspondence should be addressed.

Tel: +33 5611754 96; Fax: +33 5611759 94; Email: jean-denis.pedelacq@ipbs.fr 
a

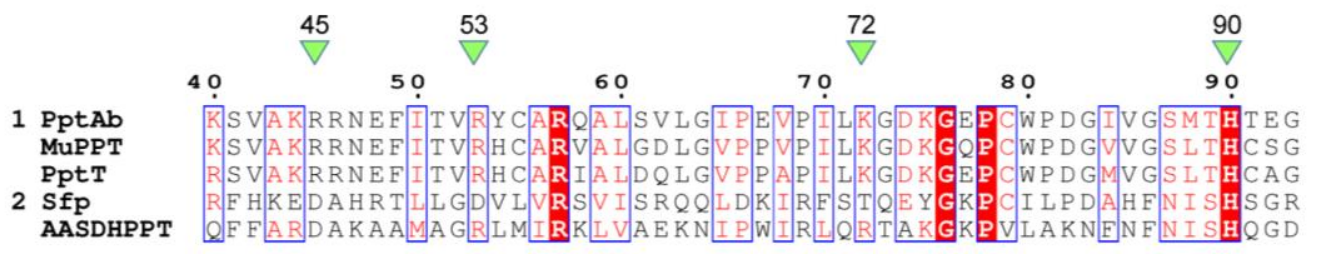

b

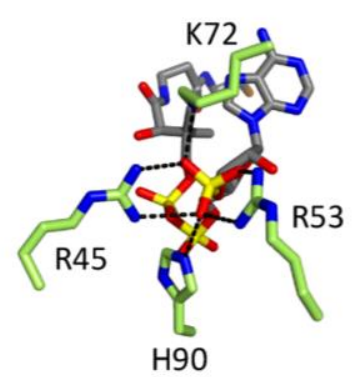

e

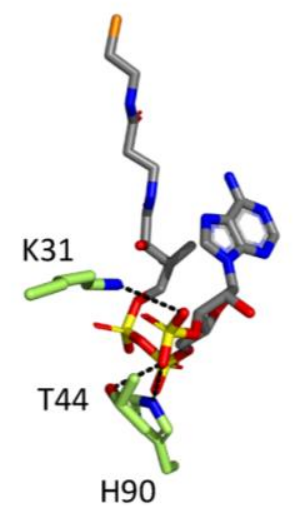

C

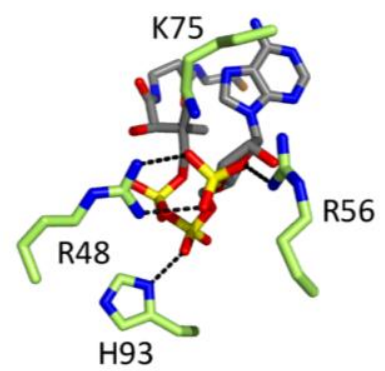

d

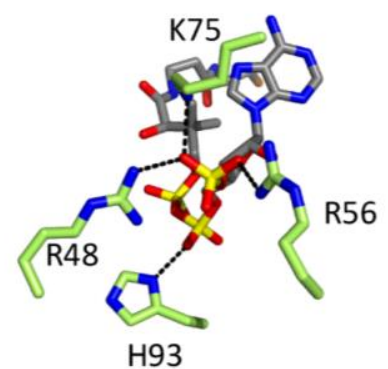

f

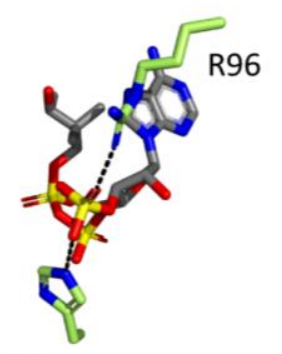

H121

Figure S1. The 3',5'-ADP moiety of CoA. Related to Figure 1. (a) Structure-based sequence alignment of PptAb from M. abscessus (UniProt entry B1MD73) with homologues from M. ulcerans (MuPPT, UniProt entry AOPQD8) and M. tuberculosis (PptT, UniProt entry O33336), extended to Sfp from B. subtilis (UniProt entry P39135) and the human AASDHPPT (UniProt entry Q9NRN7). Positions of residues making interactions with the $3^{\prime}, 5^{\prime}$-ADP moiety of COA in PptAb are indicated. The structure-based alignments were displayed using ESPRIPT (http://espript.ibcp.fr). Close-up view of the interactions between mycobacterial PPTases (b) PptAb, (c) PptT (PDB code 4u89) and (d) MuPPT (PDB code 4qjl) and the 3',5'-ADP moiety of CoA. Residues interacting with 3', 5'ADP are shown for (e) Sfp (PDB code 4mrt) and (f) AASDHPPT (PDB code 2c43). Nitrogen atoms are in blue, oxygen atoms in red, and sulfur atoms in orange. Structure figures were generated using PyMOL (The PyMOL Molecular Graphics System, Version 2.0 Schrödinger, LLC.). 


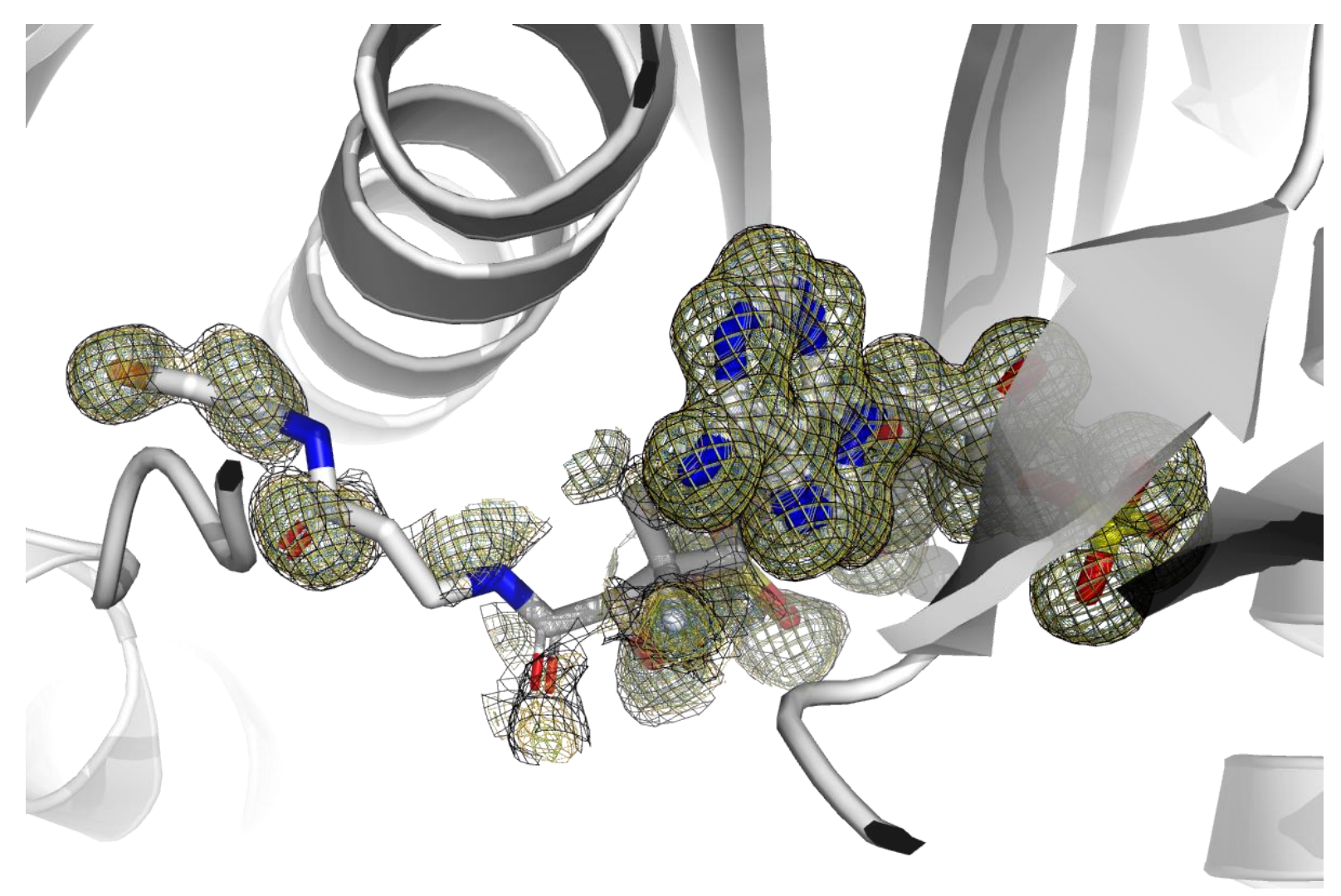

Figure S2. CoA binding at physiological pH in PptAb. Related to Figure 3. Electron density 2Fo-Fc maps contoured at $0.8,0.6,0.4$ and $0.2 \sigma$ levels are colored in blue, green, yellow and black, respectively. The figure was generated using PyMOL (The PyMOL Molecular Graphics System, Version 2.0 Schrödinger, LLC.). 

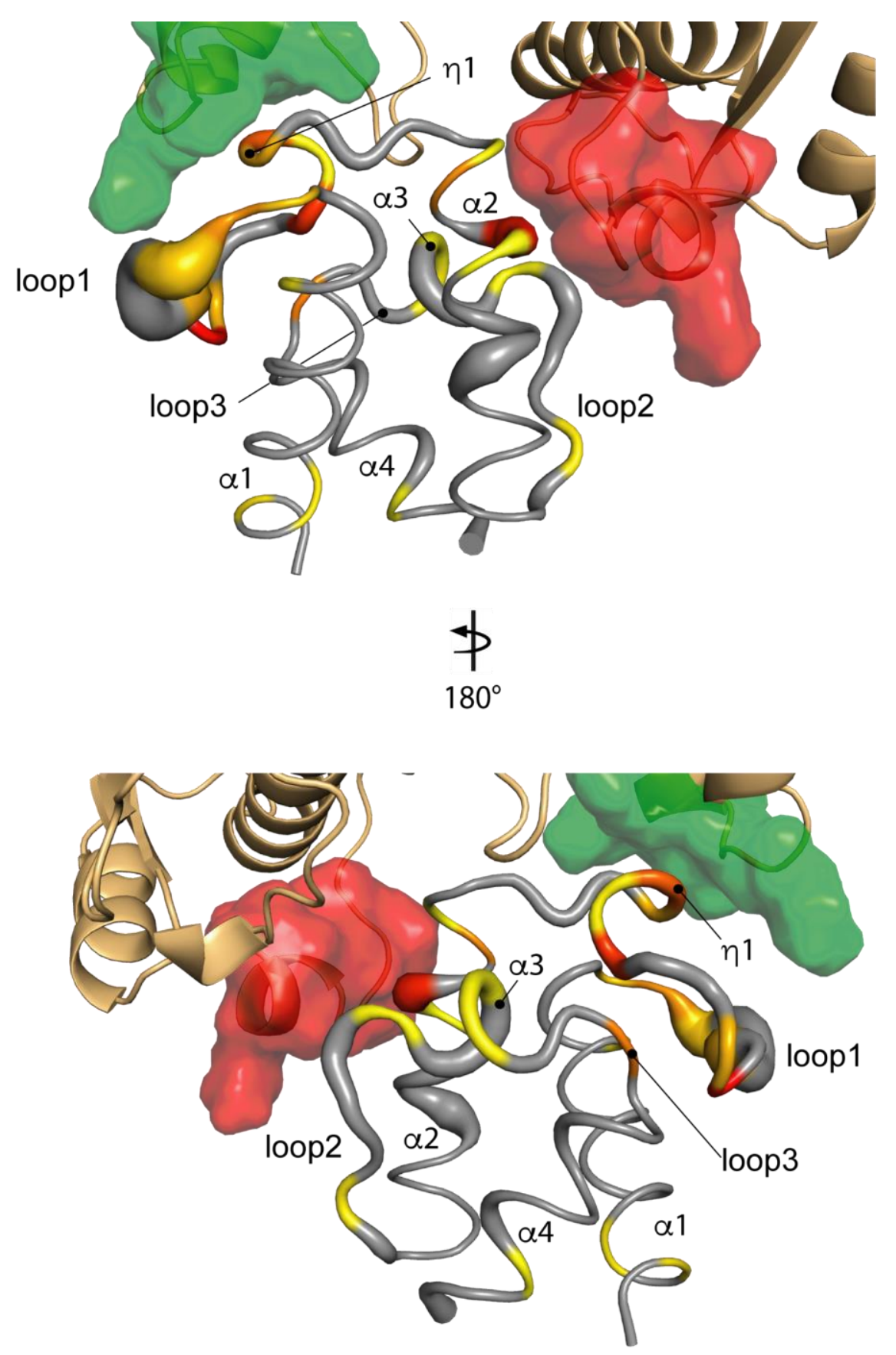

Figure S3. ACP local conformational motions spotted on the PptAb-ACP complex. Related to Figures 7 and 8. PptAb surfaces in interaction with ACP are highlighted in green (site S1) and red (site S2). The ACP dynamics is depicted by the tube thickness (for fast motions at sub-ns times scales) and from yellow to red (increasing motion values at $\mu \mathrm{s}$-ms time scales, i.e. conformational exchange). The gray color corresponds to values of $\Delta \mathrm{R}_{2 \mathrm{eff}}<5 \mathrm{~Hz}$, i.e. no or negligible conformational exchange. Note that the dynamics was measured on free ACP and not on ACP in complex with PptAb, as represented here. The ACP structure was generated using PyMOL (The PyMOL Molecular Graphics System, Version 2.0 Schrödinger, LLC.). 
a

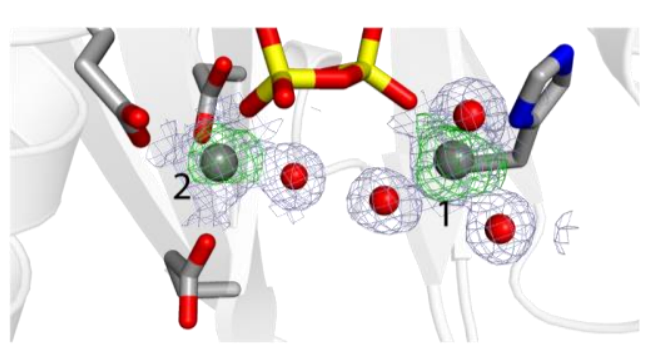

\begin{tabular}{|c|c|c|c|c|}
\hline ID & $\mathrm{X}$ & $\mathrm{Y}$ & $\mathrm{Z}$ & Peak height (sigma) \\
\hline 1 & -20.928 & -6.711 & -5.258 & 28.05 \\
\hline 2 & -23.303 & -2.712 & -9.455 & 11.58 \\
\hline 3 & -16.977 & -6.879 & 16.775 & 5.27 \\
\hline 4 & -25.785 & 13.180 & -16.046 & 4.74 \\
\hline 5 & -35.347 & 2.638 & -25.228 & 4.61 \\
\hline 6 & -10.378 & -7.877 & -20.089 & 4.53 \\
\hline 7 & -37.937 & 3.838 & -21.883 & 4.43 \\
\hline 8 & -32.870 & 16.182 & 6.266 & 4.43 \\
\hline 9 & -42.611 & -0.650 & 9.821 & 4.40 \\
\hline 10 & -6.829 & -5.845 & -0.691 & 4.39 \\
\hline
\end{tabular}

b

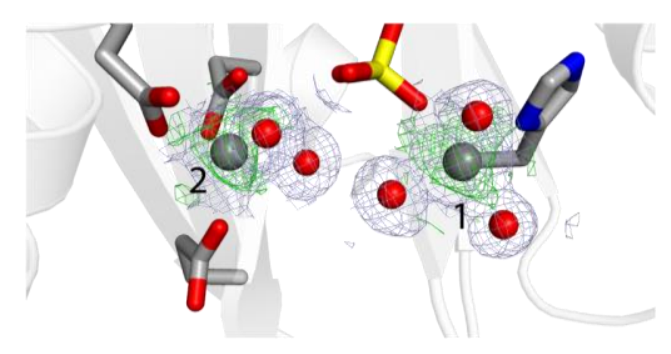

\begin{tabular}{|c|c|c|c|c|}
\hline ID & $\mathrm{X}$ & $\mathrm{Y}$ & $\mathrm{Z}$ & Peak height (sigma) \\
\hline 1 & 0.502 & 13.669 & -6.447 & 21.61 \\
\hline 2 & 4.124 & 18.141 & -9.088 & 19.55 \\
\hline 3 & 0.924 & 37.005 & -14.208 & 5.61 \\
\hline 4 & -10.936 & 19.963 & -5.486 & 5.36 \\
\hline 5 & 1.119 & 16.266 & -6.969 & 5.29 \\
\hline 6 & -16.160 & -8.333 & -13.094 & 5.19 \\
\hline 7 & -2.226 & 25.710 & -0.791 & 4.67 \\
\hline 8 & -2.524 & 18.808 & -6.615 & 4.64 \\
\hline 9 & -8.753 & 21.257 & -8.235 & 4.59 \\
\hline 10 & -1.802 & 19.866 & -10.561 & 4.54 \\
\hline
\end{tabular}

C

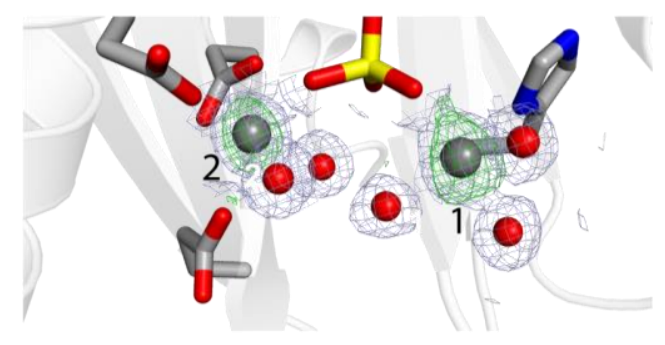

\begin{tabular}{|c|c|c|c|c|}
\hline ID & $\mathrm{X}$ & $\mathrm{Y}$ & $\mathrm{Z}$ & Peak height (sigma) \\
\hline 1 & 48.082 & 54.075 & 5.154 & 30.91 \\
\hline 2 & 50.511 & 57.833 & 8.496 & 19.21 \\
\hline 3 & 56.822 & 51.800 & 6.379 & 4.80 \\
\hline 4 & 74.802 & 68.110 & 8.290 & 4.69 \\
\hline 5 & 53.027 & 53.959 & -24.381 & 4.67 \\
\hline 6 & 62.984 & 50.378 & 8.226 & 4.42 \\
\hline 7 & 55.341 & 38.140 & -2.336 & 4.27 \\
\hline 8 & 59.471 & 60.300 & -5.084 & 4.23 \\
\hline 9 & 51.717 & 63.194 & 18.131 & 4.18 \\
\hline 10 & 38.321 & 62.579 & 8.040 & 4.17 \\
\hline
\end{tabular}

Figure S4. The cation binding sites. Related to Figures 1 and 3. The 2Fo-Fc difference maps contoured at $1.0 \mathrm{\sigma}$ level are in blue and the anomalous map peaks using our refined model missing the divalent ions are in green. Significant anomalous signal was detected for $\mathrm{Mn}^{2+}$ ions in the PDB files (a) 6qwu, (b) 6qxq, and (c) 6qxr. Structure figures were generated using PyMOL (The PyMOL Molecular Graphics System, Version 2.0 Schrödinger, LLC.). 